\title{
RECENT APPROACHES IN SENSITIVE ENANTIOSEPARATIONS BY CE
}

\section{LAURA SÁNCHEZ-HERNÁNDEZ1， MARÍA CASTRO-PUYANA², MARÍA LUISA}

MARINA $^{1}$, ANTONIO L. CREGO ${ }^{1} *$

1) Department of Analytical Chemistry, Faculty of Chemistry, University of Alcalá. Ctra. Madrid-Barcelona Km. 33.600, 28871 Alcalá de Henares (Madrid), Spain.

2) Laboratory of Foodomics, Institute of Food Science Research (CIAL), CSIC, Nicolas Cabrera 9, Campus Cantoblanco, 28049 Madrid, Spain.

Correspondence: Antonio Luis Crego, Department of Analytical Chemistry, Faculty of Chemistry, University of Alcalá, Ctra. Madrid-Barcelona Km. 33.600, 28871 Alcalá de Henares (Madrid) Spain.

E-mail: antonio.crego@uah.es

Fax: + 34-91-8854971

Keywords: CE; Chiral analysis; derivatization; detection techniques; off-line sample treatment; on-line sample preconcentration.

Non-standard abbreviations: ASEI, anion-selective exhaustive injection; CBI, cyanobenz[f]isoindole; $\mathbf{C}^{4} \mathbf{D}$, contactless conductivity detection; CMT, countermigration technique; CSEI, cation-selective exhaustive injection; DTAF, dichlorotriazinylaminofluorescein; ECL, electrochemiluminescence; EME, electro membrane extraction; FASS, field-amplified sample stacking; LLE, liquid-liquid extraction; LPME, liquid-phase microextraction; LVSS, large volume sample stacking; NAD, naphthalene-2,3-dicarboxaldehyde; NSS, normal sample stacking; PFT, partial filling technique; SDME, single drop microextraction; SLE, solid-liquid extraction; SLM, supported liquid membranes; SPME, solid-phase microextraction; tMCRB, transient moving chemical reaction boundary. 


\begin{abstract}
The latest strategies and instrumental improvements for enhancing the detection sensitivity in chiral analysis by $\mathrm{CE}$ are reviewed in this work. Following the previous reviews by García-Ruiz et al. (Electrophoresis 2006, 27, 195-212) and SánchezHernández et al. (Electrophoresis 2008, 29, 237-251; Electrophoresis 2010, 31, 28-43), this review includes those papers that were published during the period from June 2009 to May 2011. These works describe the use of off-line and on-line sample treatment techniques, on-line sample preconcentration techniques based on electrophoretic principles, and alternative detection systems to UV-Vis to increase the detection sensitivity. The application of the above-mentioned strategies, either alone or combined, to improve the sensitivity in the enantiomeric analysis of a broad range of samples, such as pharmaceutical, biological, food and environmental samples, enables to decrease the limits of detection up to $10^{-12} \mathrm{M}$. The use of microchips to achieve sensitive chiral separations is also discussed.
\end{abstract}




\section{Introduction}

Enantioselective analytical techniques have been highly demanded in the last years due to the well-known relevance of chirality in the biological activity of compounds. Over the past decades, the use of capillary electromigration techniques, to carry out enantioselective separations of chiral compounds, has extensively been studied $[1,2]$. Nowadays, there is no doubt that $\mathrm{CE}$ has evolved as an attractive and powerful separation technique providing high separation efficiency and short migration times, and needing low sample volumes. Thus, the latest advances of CE for the separation of chiral compounds in different fields, such as pharmaceutical industry, food science or environmental chemistry, among others, have been the subject of different reviews [3$12]$.

Different $\mathrm{CE}$ modes, such as EKC, MEKC, or ACE, and a huge variety of chiral selectors can be employed to achieve a chiral separation, making of CE a highly flexible technique. Among the different modes, EKC is without doubt the most used in the field of chiral separations. In the EKC mode, each enantiomer interacts in a different way with the chiral selector, so the enantiomeric discrimination is produced by a chromatographic mechanism [13-15].

In spite of the attractive properties of $\mathrm{CE}$, it can hardly meet the requirements of trace or ultratrace analysis when using UV detection because of the small injection volume and short optical path length of on-column detection. For instance, the detection sensitivity of a commercial CE-UV system is one of the most serious limitations of CE, ranging the LODs from $10^{-5}$ to $10^{-6} \mathrm{M}$ [12]. Thus, the development of strategies to obtain the detection sensitivity needed for a given application is usually required. In this regard, the approaches to enhance the sensitivity of $\mathrm{CE}$, both in conventional and chiral analysis, have been focused on three different strategies such as (i) off-line and on-line 
sample treatments, (ii) on-line sample preconcentratrion techniques based on electrophoretic or chromatographic principles, and (iii) the use of alternative detection systems to the UV/Vis detection [16-23]. Although in some cases the use of only one strategy is enough to improve the detection sensitivity, in other occasions the employ of a combination of strategies is necessary. Anyway, the combination of strategies is a current tendency since it can offer certain advantages to enhance the sensitivity as it will be deduced from the articles published in the period of time covered in this review.

With the aim of providing to the readers an update on the latest strategies and instrumental improvements developed for enhancing the sensitivity in chiral analysis by CE, this review summarizes the literature published from June 2009 to May 2011 showing the decrease in the detection limits up to $10^{-12} \mathrm{M}$, and serves as a continuation of the previous reviews on this topic published in 2006 [24], 2008 [25] and 2010 [26]. The potential of these strategies will be demonstrated on many application examples mainly aimed to the analysis of pharmaceutical, biological, food and environmental matrices.

\section{Approaches for improving the detection sensitivity}

Sensitivity is the critical point in the chiral analysis of real samples by CE. This explains why efforts to improve it are focused either on preconcentration techniques or on alternative detection systems. In this regard, the use of off-line and on-line sample treatment techniques, on-line sample preconcentration techniques and/or alternative detection systems to UV/Vis can significantly enhance both the analytical potential and the application range of chiral $\mathrm{CE}$, because of they may solve its weakest points such as poor selectivity and high LOD. 
Regarding the detection system, it is important to highlight that the combination of the partial filling technique (PFT) or the counter-migration technique (CMT) with chiral CE methodologies using UV or MS systems is often necessary to allow analyte detection. In PFT only a fraction of the capillary is filled with the buffer containing the chiral selector, while the rest of the capillary is filled with the buffer without the selector [27]. However, in CMT the capillary can be filled completely with BGE containing reverse-migrating chiral selectors since they migrate in the opposite direction to the detection system [28]. In both cases, the chiral selector never reaches the detector. Thus, this strategy is employed with the UV detector to avoid the presence of chiral selectors with a high UV absorption (e.g., in the case of selectors as macrocyclic antibiotics, such as vancomycin, which absorbs at low wavelengths, $<250 \mathrm{~nm}$ ) in the detection cell, or in the case of MS detection to avoid the contamination of the ionization source by the chiral selectors that are usually non-volatile.

Recent chiral approaches based on the above-mentioned strategies in which the LOD for enantiomers is at least $10^{-6} \mathrm{M}$ will be described in the next sections.

\subsection{Off-line sample treatment techniques}

Sample pretreatment plays a key role in the analysis of complex samples in the performance of CE. Two of the most common procedures involved to obtain a high sensitivity and selectivity are sample preconcentration and chemical derivatization. The ideal sample preparation methodology should be fast, accurate, precise, and low solvent consuming. In addition, it should be easily adapted to the field of work and employ low cost materials. Table 1 shows the sample treatment techniques used for chiral analysis by CE-UV in the period of time covered by this review. Although liquid-liquid extraction (LLE) continues being the preferred off-line sample treatment, SPE is 
demonstrating to be a powerful alternative, owing to its simplicity and economy in terms of analysis time and solvent. As it can be observed in Table 1, other treatments such as solid-liquid extraction (SLE), liquid phase micro-extraction (LPME), and derivatization have also been employed.

\subsubsection{Extraction techniques}

LLE is the most widely used sample treatment technique for clean-up and signal enhancement in routine analysis. This technique provides excellent sample clean-up for salts and biological macromolecules in spite of a broad range of other compounds may be co-extracted [38]. LLE has been employed for the extraction and concentration of drugs in culture media [29, 30] and biological samples [31] or alkaloids in herbs [32]. In addition, two chiral CE-UV methods, employing LLE and PFT, have been described in the period of time covered in this review to avoid the presence of amylose [31] or BSA [32] in the UV detector. Preconcentration factors between 3 [31] and 40 [29] and LODs up to $2 \times 10^{-8} \mathrm{M}$ were achieved.

SPE shows a general applicability and can be very efficient yielding high preconcentration factors. This type of preconcentration prior to the $\mathrm{CE}$ separation can be performed off-line, at-line, in-line or on-line, being the first one the simplest way to combine SPE and CE [39]. Among these modes, only off-line SPE has been used in the chiral methodologies included in this review. This technique has been employed for the extraction and preconcentration of ibuprofen and its metabolites in biological samples using $\mathrm{C}_{18}$ SPE cartridges [33] and nicotine alkaloids in cigarettes using a strong anion exchange sorbent [34]. Concentration factors up to 10 [33] were achieved when the eluted samples were evaporated to dryness and the residues were redissolved in a 
smaller volume of solvent in order to achieve higher preconcentration with LODs up to $2 \times 10^{-7} \mathrm{M}$.

On the other hand, the SLE of some ergostane and lanostane compounds from Antrodia camphorata fungus was carried out using a soxhlet extractor [35]. After evaporating the solvent, the residue was subjected to silica gel column chromatography and eluted with increasing polarity mixtures of n-hexane/ethyl acetate. Then, the CE method provided efficient achiral and chiral separation of the compounds isolated in one single run achieving LODs up to $1 \times 10^{-6} \mathrm{M}$.

\subsubsection{Micro-extraction techniques}

Although LLE and SPE are the most widely employed extraction methods, they are time-consuming and need a large amount of organic solvents, which is hazardous for human health and the environment. To overcome these disadvantages, the miniaturized modification of the traditional extraction methods, such as solid-phase microextraction (SPME) or liquid-phase microextraction (LPME) has been carried out [40, 41]. Between them, LPME enables excellent sample clean-up effect, high extraction efficiency and lower cost than SPME.

A mode of LPME named electro membrane extraction (EME) has recently been developed [42]. In this extraction procedure, the liquid micro-extraction is based on the application of an electrical potential across supported liquid membranes (SLM) which is faster than conventional LPME in terms of kinetic (between 3 and 11 times) [36]. In this method, one of the electrodes is placed in the donor phase, whereas the other electrode is placed in the acceptor solution inside the lumen of the fiber (see Figure 1A). Charged analytes in the donor phase migrated across the SLM towards the electrode of opposite charge in the acceptor solution. This implies that the analyte has to 
be ionic in both acceptor and donor phases. EME has been proposed as sample treatment in the drug amlodipine determination by a chiral EKC-UV method [36]. The optimization of different extraction parameters such as organic solvent, time and voltage, $\mathrm{pH}$ in the acceptor solution and in the donor phase and stirring speed, was carried out. Figure 1B shows the electropherogram corresponding to the enantiomeric separation of amlodipine in spiked and drug-free human urine and plasma samples after EME. A preconcentration factor of 124 was obtained in 15 min of sample clean-up reaching LODs of $7 \times 10^{-9} \mathrm{M}$ for each enantiomer.

\subsubsection{Derivatization}

The derivatization procedure with a suitable reagent is performed with the purpose of increasing the detection sensitivity in $\mathrm{CE}$ converting the analyte into a different compound with new chemical properties [43]. In addition, other aspects such as the separation from interfering compounds, the electrophoretic behavior (namely, peak shapes or interaction with chiral selectors) or the prevention of decomposition during the analysis, can also be improved using a derivatization procedure.

As it can be observed in Table 1, only one off-line derivatization method for chiral analysis of fenoprofen and six protein amino acids using FMOC as derivatization reagent has been described in the period of time covered in this review [37]. The derivatization reaction was carried out during 2 min at $25{ }^{\circ} \mathrm{C}$. Along with the derivatizacion process, another additional on-line sample preconcentration strategy (which will be described below) was also used. The combination of both procedures allowed to reach LODs at $10^{-9} \mathrm{M}$ level. 


\subsection{On-line sample treatment techniques}

On-line sample treatments are attractive because they minimize the consumption of samples and reagents, reduce the operation cost and can improve the precision of the analyzed samples. However, in the period of time covered by this review there is only one work published for chiral analysis by CE with UV detection. A single drop microextraction (SDME) sample treatment was coupled to a chiral EKC-UV methodology for the analysis of primary amine compounds, amphetamine, $p$-chloroamphetamine and 2amino-1,2-diphenylethanol, in human urine samples [44]. SDME is a LPME mode in which the capillary inlet surface is covered with hydrophobic octadecyltrimethoxysilane and whose extraction steps are described in Figure 2A [45]. After injecting an octanol phase, the analytes of the sample solution (donor phase) are extracted into a single drop in an acidic buffer (acceptor phase) by applying backpressure from the outlet vial and covered by the octanol solvent (see image in Figure 2A). The optimum extraction by SDME was obtained in 10 min using higher concentration of the buffer acceptor phase for real samples than for standard samples in order to avoid a loss of extraction efficiency (see Figure 2B). The developed method allowed the separation of the six enantiomers around 35 min using (+)-(18-crown-6)-tetracarboxylic acid as a chiral selector with resolutions between 1.6 and 8.0. This hyphenation provided sensitive analysis yielding preconcentration factors from 400 to 1000 -fold improvement in spiked urine samples and LODs between 2-10 x $10^{-9} \mathrm{M}[44]$, which are much lower than the cutoff values of amphetamine test in the EU and USA. 


\subsection{On-line sample preconcentration techniques}

Among the three major approaches for enhancing sensitivity in $\mathrm{CE}$, the application of on-line sample preconcentration techniques is the simplest, effective and cheapest [12]. The on-line preconcentration techniques used in EKC are mainly capillary ITP and sample stacking whereas sweeping is the most employed in MEKC. Detection sensitivity in CE can be further improved by combining two sample preconcentration techniques, for example, sweeping and stacking. During the period of time covered in this review, different strategies of stacking and sweeping have been described to increase the sensitivity in chiral CE-UV analysis, as it can be observed in Table 2. These strategies have usually been employed in combination with off-line sample treatment techniques.

\subsubsection{Stacking}

Stacking is based on the injection of a sample prepared in a matrix with a higher resistance, i.e, with minor conductivity, than the separation buffer $[23,47]$. Thus, the analytes in the sample zone are stacked when they reach the boundary between the sample zone and the running buffer zone. Sample stacking techniques include normal sample stacking (NSS), large volume sample stacking (LVSS), field-amplified sample stacking (FASS), and anion- or cation-selective exhaustive injection (ASEI or CSEI). In NSS and LVSS the injection of the sample is hydrodynamic, being a larger injection in the case of LVSS, while an electrokinetic injection is used in FASS and ASEI or CSEI. A limitation in NSS is that the optimum sample plug length that can be injected into the capillary without loss of resolution is small (over $10 \%$ of the capillary length). However, a 1/3-1/2 of the capillary can be hydrodynamically filled with the sample 
solution using LVSS, because in that case the sample matrix is pushed out of the capillary by the weak EOF prior to separation. When FASS, ASEI or CSEI are used to focus the analytes of the sample, there are no limitations in the injection volume.

A highly sensitive strategy for the enantioseparation of fenoprofen and six FMOC-amino acids by EKC-UV using vancomycin (VC) as the chiral selector was developed by combining LVSS and ASEI [37]. The experimental schedule for this strategy is shown in Figure 3A. Before injection, the capillary (total length $39 \mathrm{~cm}$ ) was fully filled with the buffer with VC. Large volume of sample (analyte anions dissolved in water) was thereafter hydrodynamically injected (34.45 mbar for $8 \mathrm{~min}$ ) to leave a short plug of the background electrolyte (BGE) in the outlet end of the capillary (only 7 $\mathrm{cm})$. Then, stacking the analytes and removing the water plug by CMT using countercurrent EOF were achieved while additional analytes are selectively injected with electrokinetic injection by applying a voltage of $-5 \mathrm{kV}$ during $12.5 \mathrm{~min}$. It should be noted that, the velocity of the anodic EOF must be lower than the cathodic velocity of the analytes to avoid them being pumped out of the capillary. Thus, a dynamically coating of the capillary with poly(N,N-dimethylacrylamide) was also carried out in order to almost suppress the EOF and to diminish the adsorption of $\mathrm{VC}$ onto the capillary wall. Electropherograms for enantioseparation obtained after on-line sample preconcentration by LVSS-ASEI are shown in Figure 3. The combination of all these strategies enabled to achieve a preconcentration factor of 1000-fold (compared with normal injection) and LODs as low as $2-21 \times 10^{-9} \mathrm{M}$. This method was successfully applied to the chiral separation of fenoprofen in a spiked river water sample.

Borges et al. evaluated the possibility of using NSS and FASS as preconcentration techniques to study the biotransformation of different adrenergic agents in Czapek culture media (endophytic fungi) with a previous LLE [29, 30]. Thus, 
NSS was performed using an injection of 50 mbar during $20 \mathrm{~s}$ for the chiral analysis of two $\beta$-adrenergic blocking agents (propranolol and its metabolite 4-hydroxypropranolol) [29]. Using carboxymethyl- $\beta-C D$ as chiral selector, baseline separations were achieved within 16 min with LODs at $10^{-7} \mathrm{M}$ level. This LOD enables the application of the developed method to study the enantioselective biotransformation of propranolol in its metabolite by the endophytic fungi after $72 \mathrm{~h}$ of incubation. A similar approach using FASS injection (10 kV during $5 \mathrm{~s}$ ) has been used to study the biotransformation of midodrine and desglymidodrine (two $\alpha$-adrenergic agonists) in Czapek culture media [30]. In this work, the chiral separation of these compounds was obtained in $11 \mathrm{~min}$, using (2,3,6-tri-O-methyl)- $\beta$-CD as chiral selector. Assuming that the studied analytes in both works are comparable, it could be affirmed that similar LODs $\left(\sim 10^{-7} \mathrm{M}\right)$ can be achieved by NSS and FASS.

Finally, an ACE method with FASS preconcentration combined with PFT (to avoid BSA reaching the detector) was optimized and validated for the determination of tetrahydropalmatine enantiomers in herb samples [32]. The enantioresolution was achieved in less than 9 min and the LODs reported for each enantiomer were around $2 \mathrm{x}$ $10^{-8} \mathrm{M}$.

\subsubsection{Sweeping}

The sweeping mechanism is based on interactions between an additive in the separation buffer, which acts as a pseudostationary phase (usually micelles, CDs or complexing agents), and the sample [48, 49]. It enables an exceptional increase in the detection sensitivity for those analytes with a high solute pseudostationary phase association constant. Sample matrix may have different or the same conductivity than the separation buffer but it is very important that the sample matrix does not contain the 
pseudostationary phase, since it is the component originating the preconcentration of the analyte by sweeping the sample matrix.

Sweeping and stacking preconcentration techniques have been compared to enhance the detection sensitivity of three chiral triazole fungicides (hexaconazole, pentaconazole, myclotbutanil) by MEKC-UV using a CD as chiral selector [46]. The stacking was carried out by injecting the sample dissolved in water at 50 mbar during 10 s, whereas sweeping strategy was achieved by dissolving the sample in buffer and injecting it during $70 \mathrm{~s}$. Both methods allowed the separation of the six enantiomers within 15 min through a BGE of 2-hydroxypropyl- $\gamma$-CD and SDS in reverse polarity. The detection sensitivity of the three fungicides was increased from 9- to 10-times by stacking whereas sweeping enabled an increase from 62- to 67-times. Besides, better LODs were achieved by sweeping $\left(3-7 \times 10^{-7} \mathrm{M}\right)$ than by stacking $\left(4-14 \times 10^{-6} \mathrm{M}\right)$.

\subsection{Detection techniques}

Chiral CE methods are usually carried out using on-column UV absorbance detection, even though its sensitivity is limited because of the short optical path length provided by the capillary diameter. This is a serious limitation especially in the analysis of samples containing low concentrations of enantiomers. For this reason, coupling of CE with alternative detection systems is of prime interest. During the period of time covered in this review, the number of publications employing alternative detection systems to the UV one, has increased compared with those reported in our previous review [26]. Thus, detection systems such as fluorescence, phosphorescence, electrochemiluminescence, conductivity and mass spectrometry have been coupled to CE for chiral analysis as it can be observed in Table 3 . 


\subsubsection{Fluorescence}

The new developments in chiral analysis with CE describe the use of LIF detection through three different excitation sources: argon-ion laser [50-52], LED [5355] and deep-UV laser [56, 57]. LIF detection with argon-ion laser continues being one of the most used and most sensitive detection techniques in CE. However, nowadays the use of LED or deep-UV lasers as excitation sources has increased. Althought LED sources reduce the overall cost of the detector, the estimated LODs using this device are higher than those obtained under the same conditions using a LIF detector with argonion laser. On the other hand, deep-UV lasers became an attractive source because of chemical derivatization is not necessary. Their main disadvantages are high costs and the specific requirements of their set-up.

As it was discussed in the previous review $[25,26]$, the main application of CE with fluorescence detectors is the chiral analysis of amino acids. In the period of time reviewed in this article, the enantioseparation of amino acids has been achieved in different matrices such as standard samples [51, 56], pharmaceuticals [52], and biological samples [50, 53-55]. As it can be seen in Table 3, a previous derivatization of the amino acids with derivatizing agents such as FITC, dichlorotriazinylaminofluorescein (DTAF), naphthalene-2,3-dicarboxaldehyde (NAD) or cyanobenz[f]isoindole (CBI) was necessary in all the cases, except in those in which a deep-UV laser was employed as excitation source.

In addition, some of the developed methodologies are combined with other offline [50] or on-line sample treatments [51], or other on-line sample preconcentration techniques [54-57] making possible to reach excellent LODs (up to $10^{-12} \mathrm{M}$ ), demonstrating that fluorescence is a powerful detection system for sensitive chiral analysis by CE. 
An example of the combination of off-line treatment and LIF detection was shown by Li et al [50]. These authors combined an off-line microdialysis method of rat brain samples with CD-MEKC-LIF for the achiral and chiral determination of several compounds (seven protein amino acids, two non-protein amino acids, and Ophosphoethanolamine) and serine, respectively. LODs $\sim 10^{-10} \mathrm{M}$ were achieved for each serine enantiomer allowing the study of the increase in the levels of the neuromodulator D-serine during cerebral ischemia/reperfusion.

Regarding on-line strategies, a CD-MEKC-LIF methodology was combined with SDME (approach described in section 2.2) to preconcentrate four FITC-amino acids, namely leucine, alanine, glutamic acid and aspartic acid, from standard samples [51]. The chiral separation was performed in a short analysis time (16 min) using a dual chiral selector system with sodium taurodeoxycholate (STC) as chiral bile salt and $\beta$ CD obtaining resolution values from 5 to 11 . Preconcentration factors around 400-fold and LODs of 3-6 x 10-11 $\mathrm{M}$ were achieved using SDME during $10 \mathrm{~min}$ (see Figure 4A). Moreover, the additional use of a micro-stirrer during the extraction allowed to reach enrichments from 3000 to 6800 -fold obtaining LODs of $1-3 \times 10^{-12} \mathrm{M}$ (See Figure 4B). As far as we know these are the lowest LODs achieved for chiral analysis of standard samples.

On the other hand, Hsieh et al. carried out the determination of leucine, valine and isoleucine (derivatized with CBI) in human urine and plasma samples [54] and aspartic acid (derivatized with NAD) in cerebrospinal fluid, beer and soymilk samples [55] by MEKC-LIF (using LED as excitation source) combined with LVSS-sweeping. For the determination of CBI-amino acids, the employ of the LVSS, allowed an increase in sensitivity of 183-316 times, as it can be observed in the electropherograms a) and d) in Figure 5A. On the other hand, the use of LVSS in the determination of aspartic acid 
provided an improvement of about 100-times (see Figure 5B). In both works, poly ethylene oxide (PEO) acted as a concentrated medium playing an important role in the stacking of enantiomers when 2-hydroxypropyl- $\beta-\mathrm{CD}$ was employed as chiral selector, allowing LODs of $\sim 2 \times 10^{-10} \mathrm{M}$.

Finally, only two works about the use of deep UV as excitation source have been described in the period of time covered in this manuscript. In these works, a laboratory made miniaturized CE system (with only $10 \mathrm{~cm}$ of capillary), using FASS and deep UV-fluorescence, was applied to the determination of tryptophan [56] and propranolol [57] in standard samples. Analysis time comparable to those obtained in microchips (60-84 s) and LODs of $7 \times 10^{-11} \mathrm{M}$ and $\sim 2 \times 10^{-10} \mathrm{M}$ for the enantiomeric determination of tryptophan and propranolol, respectively, were achieved.

\subsubsection{Phosphorescence}

An attractive detection technique in chiral $\mathrm{CE}$ in the last two years has been phosphorescence at room temperature in liquid deoxygenated solution. Three different modes can be distinguished, direct phosphorescence, where the phosphorescent analyte itself is excited by light of an appropriate wavelength, and two modes of indirect phosphorescence: sensitized and quenched. In the sensitized mode, the analyte is excited at its optimum excitation wavelength and transfers its energy to an acceptor (added to the BGE) from which phosphorescence is observed. In the quenched mode, strong phosphorophore compound (such as biacetyl or bromonaphthalene) is directly excited and its phosphorescence quantum yield is reduced by biomolecular quenching process with the analyte [69], which leads to negative peaks in the electropherogram. It should be noted that in this mode, non-phosphorescent analytes can be detected. It is also important to highlight that quenched phosphorescence is different from the indirect 
UV absorption mode, which is based on electrophoretic displacement of the BGE by the analytes.

Several works published by the Gooijer's research group have demonstrated the potential of phosphorescence as detection technique in sensitive chiral analysis. In this works, LED [58], or Nd-YAG laser [59,60] were employed as excitation sources using a sensitized phosphorescence mode. As shown in Table 3, different EKC methods coupled to phosphorescence detection were developed for the determination of camphorquinone [58, 59] and bupropion [60] in standards and different real samples. Under the optimal conditions in each case, LODs up to $4 \times 10^{-8} \mathrm{M}$ were reached.

A comparison in terms of sensitivity between direct phosphorescence and sensitized phosphorescence modes, which were employed as detection systems for the determination of bupropion enantiomers, is depicted in Figure 6 [60]. As it can be observed in this figure, an improvement in the sensitivity of 40-times was achieved using the sensitized phosphorescence mode.

\subsubsection{Electrochemiluminescence}

CE coupled to Electrochemiluminescence (ECL) detection has extensively been employed in different fields of analytical chemistry. However, it has rarely been reported for chiral separations. In spite of the advantages in sensitivity and simplicity inherent to conventional chemiluminescence methods, one of the shortcomings of ECL assay is its poor selectivity [70].

A CE-ECL methodology combined with LLE and FASS, as sample treatment and preconcentration technique, respectively, has been developed to carry out the chiral determination of dioxopromethazine in human urine samples [61]. Using $\beta$-CD as chiral selector, baseline resolution was obtained in only $13 \mathrm{~min}$, reaching a LOD of $4 \times 10^{-6} \mathrm{M}$ 
with $5 \mathrm{mM} \mathrm{Ru}(\mathrm{bpy})_{3}{ }^{2+}$ in $100 \mathrm{mM}$ phosphate buffer (pH 8.0) as ECL solution in endcolumn detection cell.

\subsubsection{Conductivity detectors}

CE with contactless conductivity detection $\left(\mathbf{C}^{4} \mathbf{D}\right)$ has progressed in the last years in terms of applications to different classes of analytes or approaches to the design of detectors [71]. The detection by $\mathrm{C}^{4} \mathrm{D}$ can be achieved both off-column and on-column. However, band broadening due to dead volume is avoided with on-column detection since the measurement is carried out directly inside the separation capillary. In this detection system, it is not necessary to remove the protective coating from fused-silica capillaries and optically non-transparent polymeric tubings may also be employed.

Recently, two CE-C $\mathrm{C}^{4}$ methodologies have been developed for the chiral separation of protein amino acids and/or hydroxy acids $[62,63]$. Thus, an EKC-C ${ }^{4} \mathrm{D}$ method has been developed for the enantioseparation of five $\alpha$-hydroxy acids and two $\alpha$-amino acids (aspartic acid and glutamic acid) using vancomycin as chiral selector [62]. Resolution values from 1.5 to 3.8 were obtained. The methodology developed in this work was applied to the determination of lactic acid enantiomers in samples of milk and yogurt, with LLE sample treatment prior to CE analysis, achieving LODs of $10^{-6} \mathrm{M}$ for each enantiomer.

On the other hand, an on-line preconcentration technique of transient moving chemical reaction boundary (tMCRB) by conductivity detection, with heart-cutting 2D-CE was carried out for the chiral separation of DL-phenylalanine, and DL-threonine in a mixture of 22 amino acids [63]. The mechanism of focusing by tMCRB (see Figure 7A) is based on a LVSS injection of solutes dissolved in basic medium (phase $\beta$ ) followed by their on-line focusing in the interface between the sample zone (phase $\beta$ ) 
and the BGE zone (phase $\alpha$ ). Then, a reaction of neutralization of the analytes occurs between the weak acidic zone (phase $\alpha$ ) and the weak alkaline zone (phase $\beta$ ). The stacked fraction from the first dimension is isolated in the capillary, and separated in the second dimension by the presence of a chiral selector $((+)-(18$-crown-6)-2,3,11,12tetracarboxylic acid) as it can be observed in Figure 7B. The use of tMCRB preconcentration technique improved the LOD by a factor of 10 and 250 for phenylalanine and threonine, respectively. Figure 7C shows the enhancement of sensitivity of phenylalanine using different injection volumes in tMCRB. An injection volume of $10 \%$ was selected as optimum since a higher volume would require the use of longer capillaries for keeping a sufficient electrophoretic separation increasing the total analysis time.

\subsubsection{MS}

One of the major breakthroughs of CE for the determination of chiral analytes in real matrices has been its online coupling to MS using ESI interfaces [21]. In fact, the hyphenation of chiral $\mathrm{CE}$ with $\mathrm{MS}$ is a powerful technique able to determine the enantiomers of chiral compounds with high selectivity and sensitivity. In addition, it is also able to solve the identification problems associated with unknown compounds in real samples since MS allows an unambiguous assignment of the different electrophoretic peaks and MS/MS spectra can also provide information about the structure of the analytes [20]. CE-MS is, along with CE-LIF, one of the most employed detection system for enhancing sensitivity in chiral CE by EKC [64-67] as it can be observed in Table 3.

One of the main drawbacks of chiral analysis by CE-MS is the contamination of the ionization source by non-volatile chiral selectors. For this reason, the CE-MS 
approaches developed in the last two years employ different strategies to avoid the contamination of the source. So, besides using the strategies of PFT [64, 65], the use of a very low concentration of chiral selector in EKC $[66,67]$, or a non ionizable chiral surfactant in MEKC [72] has been employed. Regarding MEKC mode, molecular micelles have a high weight allowing to have lower surface activity and volatility with essentially no background ions, which also enables to enhance the ESI-MS intensity. Thus, although the LOD was $\sim 3 \times 10^{-5} \mathrm{M}$, it was 3-5 times better than those obtained using UV detection.

The enantioseparation of five chiral dipeptides in spiked serum samples was optimized by an EKC-ESI-MS methodology employing a PFT strategy [64]. Chiral separations with resolutions above 2.4 in 45 min were obtained, ranging the LODs obtained from 5 to $20 \times 10^{-8} \mathrm{M}$. More recently, an EKC-ESI-MS/MS method with PFT was developed for the chiral separation of three neurotoxins derived from 1,2,3,4tetrahydroisoquinoline with the aim of investigating the in vitro formation of one of these neurotoxins, namely (R/S)-N-methylsalsolinol [65]. This work combines the strategies of PFT and CMT using an anionic CD (sulfated $\beta-C D$ ) as chiral selector, so that it migrated away from the MS ionization source during the separation, avoiding completely a possible contamination. Fast separations (less than $15 \mathrm{~min}$ ), high resolutions (from 3.0 to 4.5 ) and enough sensitivity (LODs about $10^{-6} \mathrm{M}$ level) were obtained.

On the other hand, the direct introduction of the chiral selector at very low concentration has demonstrated to be a strategy that simplifies the PFT methodology without a significant contamination or loss in sensitivity $[66,67]$. Following this idea, the enantioseparation of five protein amino acids by EKC-ESI-MS was carried out using a low quantity of modified $\beta$-CDs $(0.5 \mathrm{mM})$ [66]. The sensitivity was only $3-5$ 
times decreased by the chiral selector giving LODs of 2-19 $\times 10^{-7} \mathrm{M}$, which are higher than those obtained by a CE-LIF method developed under the same conditions (LODs from 4-9 $\left.\times 10^{-8} \mathrm{M}\right)$. The usefulness of the chiral CE-MS method was demonstrated through the detection of the main D- and L-amino acids found in different real samples including transgenic versus wild soy and vinegar. The same strategy was applied for the enantioseparation of the non-protein amino acid carnitine by EKC-ESI-MS ${ }^{2}$ [67]. A concentration of only $0.2 \%(\mathrm{w} / \mathrm{v})$ of succinyl- $\gamma-\mathrm{CD}$ was used to carry out the enantioseparation. Resolution about 3 and a LOD of $6 \times 10^{-8} \mathrm{M}$ were obtained, which was enough to detect enantiomeric impurities up to $0.002 \%$ of D-carnitine with respect to the main enantiomer (L-carnitine) in pharmaceuticals. Figure 8 shows the enantioseparation of carnitine in a pharmaceutical formulation in which the lowest percentage of D-carnitine $(0.6 \%)$ out of all the samples analyzed, was detected.

In the last two above-described methodologies, the amino acids studied were labeled with FITC [66] or FMOC [67]. This fact is because of although MS does not imply derivatization strategies, for small molecules such as amino acids, the increase in their sizes allows an improvement in the sensitivity because they appear in a higher range of $\mathrm{m} / \mathrm{z}$ where the $\mathrm{S} / \mathrm{N}$ is lower.

Finally, the coupling CE-ICP-MS has been employed, for the first time, for the development of a chiral methodology for the separation of the enantiomers of the hormone thyroxine in pharmaceuticals [68]. The method was based on ligand-exchange mechanism using a $\mathrm{Cu}(\mathrm{II}) / \mathrm{L}$-proline complex as chiral selector and the monitoring of iodine $\left({ }^{127} \mathrm{I}\right)$ as specific detection. The chiral separation was achieved in less than 15 min with a resolution around 4 and the LODs obtained $\left(\sim 4 \times 10^{-7}\right)$ were similar to those reached by conventional UV detection. 


\section{Microchips}

Chiral microchip CE is gaining popularity due to the development of simple micro-fabrication methods [73]. The high electric fields in combination with the short separation lengths can produce analysis times of seconds. However, microchip CE also suffers from low sensitivity for similar reasons as in conventional $\mathrm{CE}$ and very few works have been reported using UV detection. For instance, using a microchip EKCUV method for the enantioseparation of the drug naproxen employing methyl- $\beta-C D$ as chiral selector, the LOD was $10^{-5} \mathrm{M}$ which is 2.5 times lower that the LOD obtained, under similar conditions, by conventional EKC-UV [74]. Nevertheless, the separation of (R,S)-naproxen by microchip CE was achieved in just $20 \mathrm{~s}$ with better resolution and similar precision than EKC-UV, showing the potential of this device.

The trend in chiral microchip electrophoresis, as in conventional chiral $\mathrm{CE}$, is the combination of different strategies to improve the sensitivity in order to carry out its application in the analysis of real samples, which have had little attention up to now. Thus, Huang et al. [75] have developed a microchip MEKC-LIF methodology for the chiral separation of tyrosine previously derivatized with FITC. The enantioresolution was obtained in around 2 min with a LOD of $3 \times 10^{-8} \mathrm{M}$ which allowed the determination of D-tyrosine in human plasma samples previously extracted by LLE.

\section{Concluding remarks}

This review article summarizes the developments reported to enhance the sensitivity in enantioseparations by $\mathrm{CE}$ in the last two years and their main applications. CE offers a very high flexibility for enantiomeric separations, due to the wide variety of chiral selectors that can be used into the CE systems and the different working modes 
that can be employed. EKC and MEKC were the most employed modes to achieve enantioseparations by CE although ACE has also been employed.

$\mathrm{CE}$ needs of powerful strategies to increase the limited sensitivity of detection achieved in enantioseparations. Thus, techniques based on effective off-line and on-line sample pretreatment offer enhanced sensitivity and selectivity. In addition, the development of micro-extraction techniques allows faster and cheaper procedures than the conventional ones in terms of solvent and preconcentration factor. In this regards, enrichments up to 6800-fold have been achieved.

Among the on-line capillary preconcentration techniques, stacking has predominated because of its relative simplicity compared to other procedures such as sweeping, achieving significant improvements in sensitivity when a combination of two sample preconcentration techniques are used, for example, LVSS and ASEI, for which the best LODs was obtained (up to $2 \times 10^{-9} \mathrm{M}$ ).

However, it is clear that the major trend in the last two years has been the use of chiral CE methodologies using alternative and more sensitive detection methods than UV detection, mainly LIF or MS detection. It should be noted that, combinations of these kind of detectors with other strategies to increase the sensitivity such as, off-line sample treatment techniques and on-line preconcentration techniques, especially combinations of two or more of them, is expected to have greater impact on the future work because LODs up to $10^{-12} \mathrm{M}$ have been achieved. 


\section{Acknowledgements}

Authors thank the Spanish Ministry of Science and Innovation (project CTQ200909022) and the Comunidad Autónoma of Madrid (Spain) and European funding from FEDER programme (project S2009/AGR-1464, ANALISYC-II). They also thank the University of Alcalá and the Comunidad Autónoma of Madrid for project CCG10-UAH/AGR-5950. Laura Sánchez-Hernández thanks the Comunidad Autónoma of Madrid for her research contract. Maria Castro Puyana thanks the Spanish Ministry of Science and Innovation for her Juan de la Cierva contract (JCI-2009-05297). 


\section{References}

[1] Chankvetadze, B., J. Chromatogr. A 2007, 1168, 45-70.

[2] Fanali, S., Electrophoresis 2009, 30, S203-S210.

[3] Mikus, P., Maráková, K., Electrophoresis 2009, 30, 2773-2802.

[4] Kirschner, D. L., Green, T. K., J. Sep. Sci. 2009, 32, 2305-2318.

[5] Prokhorova, A. F., Shapovalova, E.N., Shpigun, O.A., J. Pharm. Biomed. Anal. $2010,53,1170-1179$.

[6] Suntornsuk, L., Anal. Bioanal. Chem. 2010, 398, 29-52.

[7] Sekhon, B. S., Int, J. Pharm. Tech. Res. 2010, 2, 1584-1594.

[8] Herrero, M., García-Cañas, V., Simó, C., Cifuentes, A., Electrophoresis 2010, $31,205-228$.

[9] Pérez-Fernández, V., García, M. A., Marina, M. L., J. Chromatogr. A 2010, $1271,968-989$.

[10] Caslavska, J., Thormann, W., J. Chromatogr. A 2011, 1218, 588-601.

[11] Schmid, M. G., Gübitz, G., Anal. Bioanal. Chem.2011, 400, 2305-2316.

[12] Lu, H., Chen. G., Anal. Methods 2011, 3, 488-508.

[13] Gubitz, G., Schmid, M. G., J. Chromatogr. A 1997, 792, 179-225.

[14] Chankvetadze, B., J. Chromatogr. A 1997, 792, 269-295.

[15] Chankvetadze, B., Blaschke, G, J. Chromatogr. A 2001, 906, 309-363.

[16] Kastsova, L. A., Bessonova, E. A., J. Anal. Chem. 2009, 64, 326-337.

[17] Almeda, S., Arce, L., Valcárcel, M., Curr. Anal. Chem. 2010, 6, 126-143.

[18] Mikus, P., Maráková, K., Curr. Anal. Chem. 2010, 6, 76-100.

[19] Somsen, G. W., Mol, R., de Jong, G. J., J. Chromatogr. A 2010, 1217, 39783991.

[20] Simó, C., García-Cañas, V., Cifuentes, A., Electrophoresis 2010, 31, 1442-1456. 
[21] Pantucková, P., Gebauer, P., Bocek, P., Krivánková, L., Electrophoresis 2011, $32,43-51$.

[22] Breadmore, M. C., Dawod, M., Quirino, J. P., Electrophoresis 2011, 32, 127148.

[23] Malá, Z., Genauer, P., Bocek, P., Electrophoresis 2011, 32, 116-126.

[24] García-Ruiz, C., Marina, M. L., Electrophoresis 2006, 27, 195-212.

[25] Sánchez-Hernández, L., Crego, A. L., Marina, M. L., García-Ruiz, C., Electrophoresis 2008, 29, 237-251.

[26] Sánchez-Hernández, L., García-Ruiz, C., Marina, M. L., Crego, A. L., Electrophoresis 2010, 31, 28-43.

[27] Tanaka,Y., Terabe, S., J. Chromatogr. A 1995, 694, 277-284.

[28] Chankvetadze, B., Endresz, G., Blaschke, G., Electrophoresis 1994, 15, 804807.

[29] Borges, K. B., Pupo, M. T., Bonato, P. S., Electrophoresis 2009, 30, 3910-3917.

[30] Barth, T., Pupo, M. T., Borges, K. B., Okano, L. T., Bonato, P. S., Electrophoresis 2010, 31, 1521-1528.

[31] Wei, W.-L., Guo, B.-Y., Lin, J.-M., J. Chromatogr. A 2009, 1216, 1484-1489.

[32] Ye, H., Yu, L., Xu, X., Zheng, C. Lin, W., Liu, X., Chen, G., Electrophoresis 2010, 31, 2049-2054.

[33] Karazniewicz-Lada, M., Luczak, M., Glówka F., Xenobiotica 2009, 39, 476-485.

[34] Kodama, S., Morikawa, A., Nakagomi, K., Yamamoto, A., Sato, A., Suzuki, K., Yamashita, T., Kemmei, T., Taga, A., Electrophoresis 2009, 30, 349-356.

[35] Majid, E., Male, K. B., Tzeng, Y.-M., Omamogho, J. O., Glennon, J. D., Luong, J. H. T., Electrophoresis 2009, 30, 1967-1975.

[36] Nojavan, S., Fakhari, A. R., J. Sep. Sci. 2010, 33, 3231-3238. 
[37] Wang, Z., Liu, C., Kang, J., J. Chromatogr. A, 2011, 1218, 1775-1779.

[38] Vandervlis, E., Mazereeuw, M., Tjaden, U., Irth, H., Vandergreef, J., J. Chromatogr. A 1994, 687, 333-341.

[39] Ramautar, R., Somsen, G. W., de Jong, G. J., Electrophoresis 2010, 31, 44-54.

[40] Li, S., Weberm S.G., Anal. Chem. 1997, 69, 1217-1222.

[41] Pedersen-Bjergaard, S., Rasmussen, K. E., Electrophoresis 2000, 21, 579-585.

[42] Pedersen-Bjergaard, S., Rasmussen, K. E., J. Chromatogr. A 2006, 1109, 183190.

[43] Pentoney, S. L., Huang, X., Bur, D. S., Zare, R. N., Anal. Chem. 1988, 60, $2625-$ 2629

[44] Choi, K., Kim, J., Jang, Y.O., Chung, D. S., Electrophoresis 2009, 30, 29052911.

[45] Choi, K., Kim, S. J., Jin, Y. G., Jang, Y. O., Kim, J.-S., Chung, D. S., Anal. Chem. 2009, 81, 225-230.

[46] Ibrahim, W. A. W., Hermawan, D., Sanagi, M. M., Aboul-Enein, H. Y., Chromatographia 2010, 71, 305-309.

[47] Vinther, A., Everaerts, F. M., Sareberg, H., J. High Resolut. Chrom. 1990, 13, 639-642.

[48] Quirino, J. P.; Terabe, S., Science 1998, 282, 465-68.

[49] Aranas, A.T., Guidote, A. M., Quirino, J. P., Anal. Bioanal. Chem. 2009, 394, $175-185$.

[50] Li, H., Li, C., Yan, Z.-Y., Yang, J., Che, H., J. Neurosci. Methods 2010, 189, 162-168.

[51] Liang, G., Choi, K., Ahmed, A. Y. B. H., ALOthman, Z. A., Chung, D. S., Anal. Chim. Acta 2010, 677, 37-42. 
[52] Wang, S., Fan, L., Cui, S., J. Sep. Sci. 2009, 32, 3184-3190

[53] Li, S., Yu, Q., Lu, X., Zhao, S., J. Sep. Sci. 2009, 32, 282-287.

[54] Tseng, W.-L., Hsu, C.-Y., Wu, T.-H., Huang S.-W., Hsieh, M.-M., Electrophoresis 2009, 30, 2558-2564.

[55] Lin, K.-C., Hsieh, M.-M., Chang, C.-W., Lin, E.-P., Wu, T.-H., Talanta 2010, $82,1912-1918$

[56] Belin, G. K., Gärtner, V., Seeger S., J. Chromatogr. B 2009, 877, 3753-3756.

[57] Belin, G. K., Seeger, S., Electrophoresis 2009, 30, 2565-2571.

[58] Lammers, I., Buijs, J., van der Zwan, G., Ariese, F., Gooijer, C., Anal. Chem. 2009, 81, 6226-6233.

[59] Lammers, I., Buijs, J., Ariese, F., Gooijer, C., Anal. Chem. 2010, 82, 9410-9417.

[60] Castro-Puyana, M., Lammers, I., Buijs, J., Gooijer, C., Ariese, F., Electrophoresis 2010, 31, 3928-3936.

[61] Li, X., Song, B., Yuan, B., Sun, J., You, T., Chromatographia 2009, 70, 12911293.

[62] Pormsila, W., Gong, W. Y., Hauser, P. C., Electrophoresis 2010, 31, 2044-2048.

[63] Anouti, S., Vandenabeele-Trambouze, O., Cottet, H., Electrophoresis 2010, 31, 1029-1035.

[64] Xia, S., Zhang, L., Lu, M., Qiu, B., Chi, Y., Chen, G., Electrophoresis 2009, 30, $2837-2844$.

[65] Wu, H., Yuan, B., Liu, Y.-M., J. Chromatogr. A, 2011, 1218, 3118-3123.

[66] Giuffrida, A., León, C., García-Cañas, V., Cucinotta, V., Cifuentes, A., Electrophoresis 2009, 30, 1734-1742.

[67] Sánchez-Hernández, L., García-Ruiz, C., Crego, A. L., Marina, M. L., J. Pharm. Biomed. Anal. 2010, 53, 1217-1223. 
[68] Kang, J., Kutscher, D., Montes-Bayón, M., Blanco-González, E., Sanz-Medel, A., Electrophoresis 2009, 30, 1774-1782.

[69] Kuijt, J., Ariese, F., Brinkman, U. A. T., Gooijer C., Anal. Chim. Acta 2003, 488, 135-177.

[70] Guo, L., Fu, F., Chen, G., Anal. Bioanal. Chem. 2011, 399, 3323-3343.

[71] Kuban, P., Hauser, P. C., Electrophoresis 2011, 32, 30-42.

[72] Wang, B., He, J., Shamsi, S. A., J. Chromatogr. Sci. 2010, 48, 572-583.

[73] Nagl, S., Schulze, P., Ludwig, M., Belder, D., Electrophoresis 2009, 30, 2765 2772

[74] Guihen, E., Hogan, A.-M., Glennon, J. D., Chirality 2009, 21, 292-298.

[75] Huang, Y., Shi, M., Zhao, S., Liang, H., J. Chromatogr. B 2011, 879, 191-196. 


\section{Figure captions}

Figure 1. (A) Schematic illustration of the setup for EME. (B) Electropherograms obtained after EME from spiked with amlodipine and drug-free human urine and plasma (spiked sample solution: $50 \mathrm{ng} / \mathrm{mL}$ of each enantiomer). Extraction conditions: $\mathrm{HCl} 10 \mathrm{mM}$ as the acceptor and donor phases, $200 \mathrm{~V}$ voltage, $1000 \mathrm{rpm}$ stirring rate, SLM: nitrophenyl octylether. Electrophoretic conditions: fused silica capillary, $60 \mathrm{~cm}$ total length (50 cm effective length) and $75 \mu \mathrm{m}$ id; BGE, $100 \mathrm{mM}$ phosphate buffer (pH 2.0) containing $5 \mathrm{mM} \mathrm{HP}-\alpha-\mathrm{CD}$; applied voltage, $+20 \mathrm{kV}$; temperature, $25^{\circ} \mathrm{C}$; injection, 60 mbar for $5 \mathrm{~s}$; UV detection, $214 \mathrm{~nm}$. Peaks, R-amlodipine and S-amlodipine. Reprinted from [36] with permission. Copyright Wiley-VCH Verlag BmbH KGaA.

Figure 2. (A) Procedure of SDME-CE: (1) Injection of the organic phase (octanol), (2) 2-phase drop formation by ejection of the organic phase (include the image of a 2-layer drop formation), (3) extraction of the sample in the donor phase into the acceptor phase, and (4) injection of the enriched acceptor phase into the capillary for CE chiral separation (reprinted from [45]. Copyright (2009), with permission from ACS); (B) Comparison of the electropherograms for the buffer acceptor concentration in urine sample enriched by 10 min SDME: (a) standard solution (pH 13.7) to the acceptor phase of $50 \mathrm{mM}$ Bis-Tris/CA ( $\mathrm{pH} 4.0$ ), (b) urine ( $\mathrm{pH}$ 13.7) to $50 \mathrm{mM}$ Bis-Tris/CA ( $\mathrm{pH} 4.0$ ), and (c) urine ( $\mathrm{pH}$ 13.7) to $120 \mathrm{mM}$ Bis-Tris/CA (pH 4.0). Electrophoretic conditions: fused silica capillary, $60 \mathrm{~cm}$ total length (50 $\mathrm{cm}$ effective length) and $50 \mu \mathrm{m}$ id; BGE, $50 \mathrm{mM}$ Bis-Tris/CA containing $0.8 \mathrm{mM} 18 \mathrm{C}_{6} \mathrm{H}_{4}(\mathrm{pH} 4.0)$; applied voltage, $+25 \mathrm{kV}$; temperature, $25^{\circ} \mathrm{C}$; injection, 0.3 psi for $5 \mathrm{~s}$; UV detection, $200 \mathrm{~nm}$. Peaks: (1) $500 \mathrm{nM}$ 
amphetamine, (2) $200 \mathrm{nM}$ p-chloroamphetamine, (3) $600 \mathrm{nM}$ 2-amino-1,2diphenylethanol, (*) creatinine. Reprinted from [44] with permission. Copyright WileyVCH Verlag BmbH KGaA.

Figure 3. (A) Schematic representation for LVSS-ASEI and enantioseparation: (i) filling the capillary with the buffer containing vancomycin (:)); (ii) hydrodynamic injection of the sample by pressure; (iii) stacking the sample and removing the water plug by EOF and injection of more sample by ASEI; (iv) enantioseparation. (B) and (C) Electropherograms for enantioseparation of FMOC-Ala, fenoprofen (Feno) and other FMOC-amino acids after sample concentration with LVSS-ASEI. Conditions: fused silica capillary, $50 \mu \mathrm{m}$ id $\times 39 \mathrm{~cm}(29 \mathrm{~cm}$ to detection window); BGE used for filling the capillary before injection, $100 \mathrm{mM}$ Tris-H3PO4 (pH 6.0) containing 2 mmol/L vancomycin; BGE used for separation, 100 mM Tris-H3PO4 (pH 6.0); samples was injected by pressure at 34.47 mbar for $8 \mathrm{~min}$, followed by electrokinetic injection by applying voltage of $-5 \mathrm{kV}$ for $12.5 \mathrm{~min}$; detection wavelength, $214 \mathrm{~nm}$; column temperature, $20^{\circ} \mathrm{C}$; applied voltage for separation, $-15 \mathrm{kV}$. Concentrations for each enantiomer: fenoprofen (Feno), $2.5 \mathrm{ng} / \mathrm{mL}$, and all FMOC-amino acids, $13.5 \mathrm{ng} / \mathrm{mL}$. Adapted from [37]. Copyright (2011), with permission from Elsevier.

Figure 4. (A) Electropherograms of FITC-AAs (a) $250 \mathrm{nM}$ without SDME (b) $2.5 \mathrm{nM}$ enriched by 10 min SDME. (B) Electropherograms of $2.5 \mathrm{nM}$ FITC-AAs (a) enriched by $10 \mathrm{~min}$ SDME without stirring, and (b) enriched by $10 \mathrm{~min}$ SDME with stirring. Electrophoretic conditions: fused silica capillary, $60 \mathrm{~cm}$ total length $(50 \mathrm{~cm}$ effective length) and $25 \mu \mathrm{m}$ id; BGE, $80 \mathrm{mM}$ borate $(\mathrm{pH} 9.3)+12 \mathrm{mM} \beta-\mathrm{CD}+8 \mathrm{mM}$ STC; applied voltage, $+25 \mathrm{kV}$; temperature, $25^{\circ} \mathrm{C}$; injection, 0.3 psi for $2 \mathrm{~s}$; LIF detection, 488 
and $520 \mathrm{~nm}$ (excitation and emission wavelengths). Peaks: 1. D-Leu, 2. L-Leu, 3. DAla, 4. L-Ala, 5, D-Glu, 6. D-Asp, 7. L-Glu, 8. L-Asp. Reprinted from [51]. Copyright (2010), with permission from Elsevier.

Figure 5. (A) Electropherograms of $0.1 \mu \mathrm{M}$ CBI-DL-amino acids by on-line preconcentration when the sample was hydrodynamic injected at 20 -cm height for (a) 3 s, (b) $90 \mathrm{~s} \mathrm{(c)} 120 \mathrm{~s}$ and (d) $180 \mathrm{~s}$. Electrophoretic conditions: fused silica capillary, 50 $\mathrm{cm}$ total length (40 cm effective length) and $75 \mu \mathrm{m}$ id; Before separation, the capillary was filled with a solution of $100 \mathrm{mM}$ tris-borate, $50 \mathrm{mM} \mathrm{HP}-\beta-\mathrm{CD}$, and $150 \mathrm{mM}$ SDS, whereas buffer vials contain $0.5 \% \mathrm{w} / \mathrm{v}$ PEO, $20 \mathrm{mM}$ tris-borate, $150 \mathrm{mM}$ SDS, and 50 $\mathrm{mM}$ HP- $\beta-\mathrm{CD}$; applied voltage, $+10 \mathrm{kV}$; temperature, $25^{\circ} \mathrm{C}$; LIF detection, $410 \mathrm{~nm}$ (excitation wavelength). Peaks: 1. D-Val; 2. L-Val; 3. D-Ile; 4. D-Ile; 5. D-Leu; 6. LLeu. Reprinted from [54] with permission. Copyright Wiley-VCH Verlag BmbH KGaA. (B) Electropherograms of $0.1 \mu \mathrm{M}$ NAD-DL-Asp enantiomers by on-line preconcentration when were hydrodynamic injected (a) $25 \mathrm{~nL}$, (b) $150 \mathrm{~nL}$, (c) $300 \mathrm{~nL}$, and (d) $600 \mathrm{~nL}$ of the sample. Electrophoretic conditions: fused silica capillary, $60 \mathrm{~cm}$ total length (50 cm effective length) and $75 \mu \mathrm{m}$ id; Before separation, the capillary was filled with a solution of $150 \mathrm{mM}$ tris-borate, $60 \mathrm{mM} \mathrm{HP}-\beta-\mathrm{CD}$, and $150 \mathrm{mM}$ SDS, whereas buffer vials contain $0.6 \%$ w/v PEO, $150 \mathrm{mM}$ tris-borate, $150 \mathrm{mM}$ SDS, and 60 $\mathrm{mM}$ HP- $\beta-\mathrm{CD}$; applied voltage, $+8 \mathrm{kV}$; temperature, $25^{\circ} \mathrm{C}$; LIF detection, $410 \mathrm{~nm}$ (excitation wavelength). Peaks: 1. D-Val, 2. L-Val. Reprinted from [55]. Copyright (2010), with permission from Elsevier. 
Figure 6. Electropherograms showing the separation of bupropion enantiomers $(1.5 \mathrm{x}$ $10^{-5} \mathrm{M}$ each) using direct (A) or sensitized indirect (B) phosphorescence modes. The decays for the enantiomers at the electrophoretic peak maxima for both detection modes are also shown. Electrophoretic conditions: fused silica capillary, $90 \mathrm{~cm}$ total length $(50$ cm effective length) and $75 \mu \mathrm{m}$ id; BGE, without biacetyl (A) or with $2 \times 10^{-4} \mathrm{M}$ biacetyl (B) with $5 \mathrm{mM}$ sulfated- $\alpha-\mathrm{CD}$ in $25 \mathrm{mM}$ phosphate (pH 3.0); applied voltage, $-20 \mathrm{kV}$; temperature, $20^{\circ} \mathrm{C}$; injection, 50 mbar for $0.16 \mathrm{~min}$; Phosphorescence detection, $266 \mathrm{~nm}$ (excitation wavelengths); neutral density filter, 3\%; cut-off filter, $300 \mathrm{~nm}$; band pass filter, (A) 415-585 or (B) 490-600 nm. The BGE was purged with nitrogen to remove oxygen. Reprinted from [60] with permission. Copyright Wiley-VCH Verlag BmbH KGaA.

Figure 7. (A) Mechanism of focusing by tMCRB. (a) Injection of analytes (anionic) diluted in alkaline phase (ammonium formate, phase $\beta$ ) by hydrodynamic pressure. The electrolyte of separation is acidic (phase $\alpha$ ). (b) Formation of $\alpha \beta$ boundary where the analytes stack by application of a voltage. It symbolized the reaction of neutralization between weak acidic phase consisting of acetic acid $(\mathrm{H}+)$ and weak alkaline phase consisting of ammonium formate $\left(\mathrm{OH}^{-}\right)$. Analytes are anionic in phase $\beta$ and cationic in phase $\alpha$. (B) Principle of the on-line tMCRB preconcentration combined with heartcutting 2D-CE for the achiral (first dimension) and chiral separation (second dimension) of complex mixtures in a single capillary: (1) Hydrodynamic injection of the sample diluted in alkaline phase for tMCRB preconcentration; (2) Achiral separation of stacked amino acids and evacuation of fraction $\mathrm{A}$ in the first dimension; (3) Introduction of the second dimension electrolyte (BGE 2) by hydrodynamic flow; (4) Isolation of fraction 
B in the capillary after evacuation of fraction $C$ by the inlet end of the capillary; (5) chiral resolution of the fraction $\mathrm{B}$ in the second dimension of the separation. (C) Electropherograms showing the on-line focusing by tMCRB in non-chiral CE separation of a mixture containing 22 native amino acids at $1 \mathrm{mM}$ of each enantiomer for different hydrodynamic injection volumes: 50 psi for $0.4 \mathrm{~min}$ (5\% of the total capillary volume); for $0.8 \mathrm{~min}(10 \%)$; for $1.2 \mathrm{~min}(15 \%$, for $1.6 \mathrm{~min}(20 \%)$. Electrophoretic conditions: fused silica capillary, $60 \mathrm{~cm}$ total length $(46.6 \mathrm{~cm}$ effective length) and $10 \mu \mathrm{m} \mathrm{id}$; BGE, $2.3 \mathrm{M}$ acetic acid; applied voltage, $+30 \mathrm{kV}$; temperature, $25^{\circ} \mathrm{C}$; Conductivity detection. Peak F, DL-Phe. Reprinted from [63] with permission. Copyright Wiley-VCH Verlag BmbH KGaA.

Figure 8. CE-ESI-MS ${ }^{2}$ EIE for a pharmaceutical sample and the corresponding $\mathrm{MS}^{2}$ spectra for the peaks of L- and D-carnitine. Electrophoretic conditions: fused silica capillary, $100 \mathrm{~cm}$ total length and $50 \mu \mathrm{m}$ id; BGE, $0.5 \mathrm{M}$ ammonium formate ( $\mathrm{pH} 2.5$ ) with $0.2 \%(\mathrm{~m} / \mathrm{v})$ succ- $\gamma-\mathrm{CD}$; applied voltage, $+25 \mathrm{kV}$; temperature, $25^{\circ} \mathrm{C}$; injection by pressure at 50 mbar $\times 12$ s. ESI conditions: positive ion mode; spray voltage, $4.5 \mathrm{kV}$; sheath liquid, isopropanol/water $(50 / 50 \mathrm{v} / \mathrm{v})$ with $0.1 \%$ formic acid at $3.3 \mu \mathrm{L} / \mathrm{min}$; drying gas flow, $5 \mathrm{~L} / \mathrm{min}$; drying temperature, $300{ }^{\circ} \mathrm{C}$; nebulizer pressure, 2 psi; compound stability, $50 \%$. MS ${ }^{2}$ transitions, $384 \rightarrow 179 \mathrm{~m} / \mathrm{z}$; width, $4 \mathrm{~m} / \mathrm{z}$; fragmentation amplitude, 1.20 V. Reprinted from [67]. Copyright (2010), with permission from Elsevier. 
Figure 1.

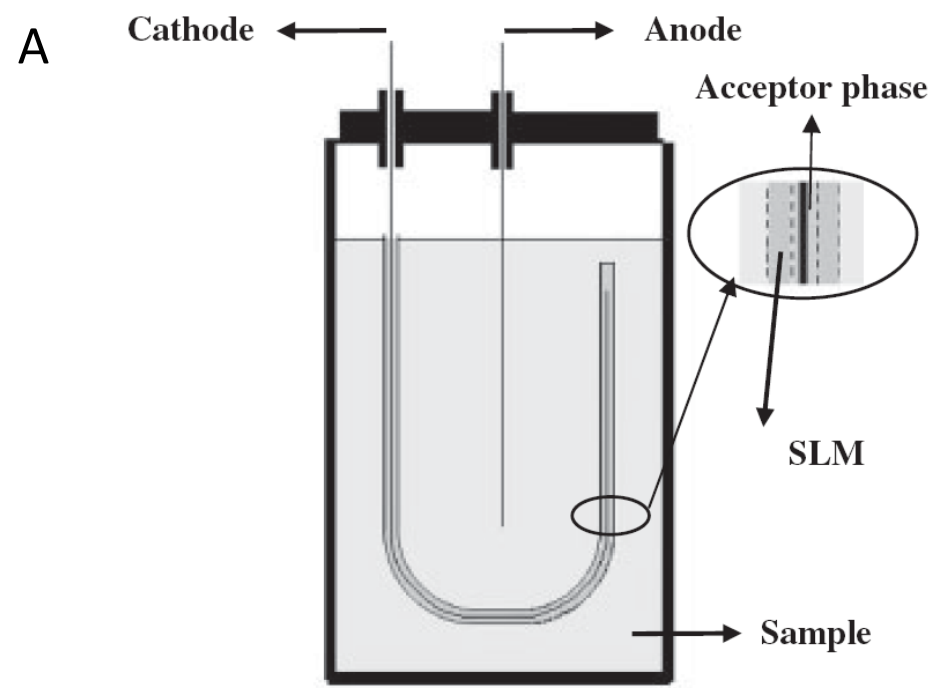

B
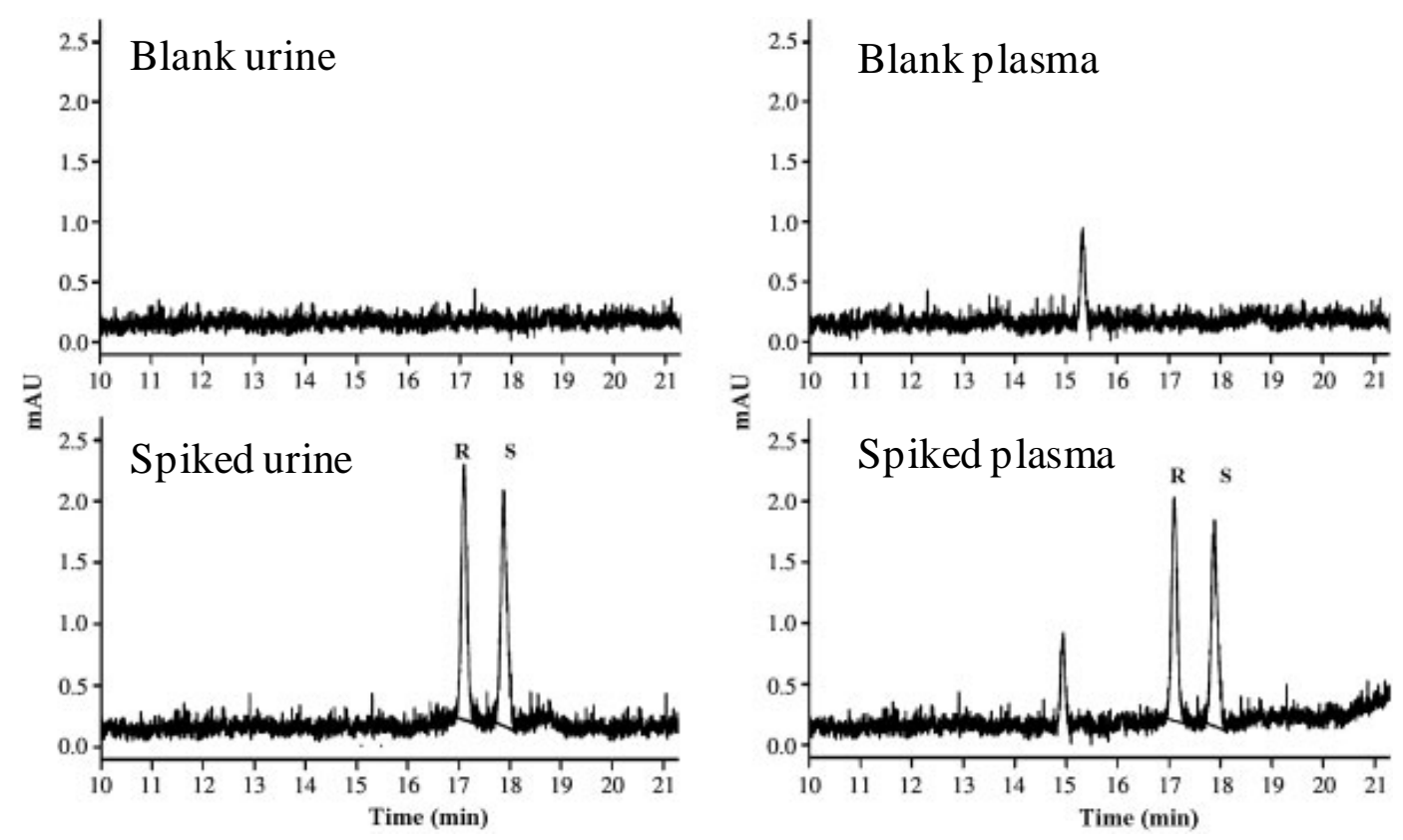
Figure 2

A

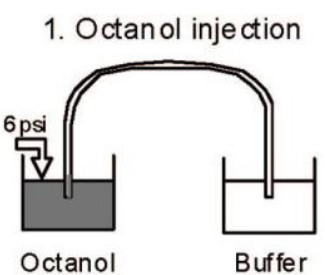

2. Drop formation

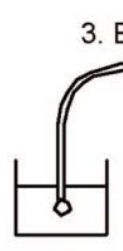

Sample
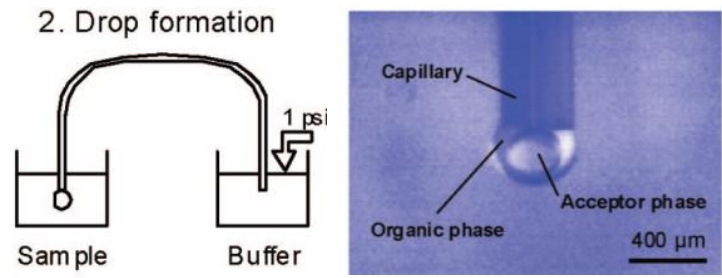

4. In jection

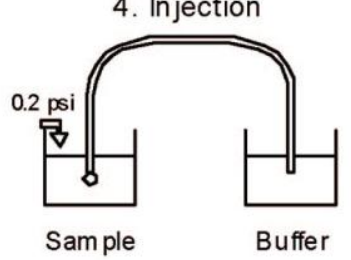

B

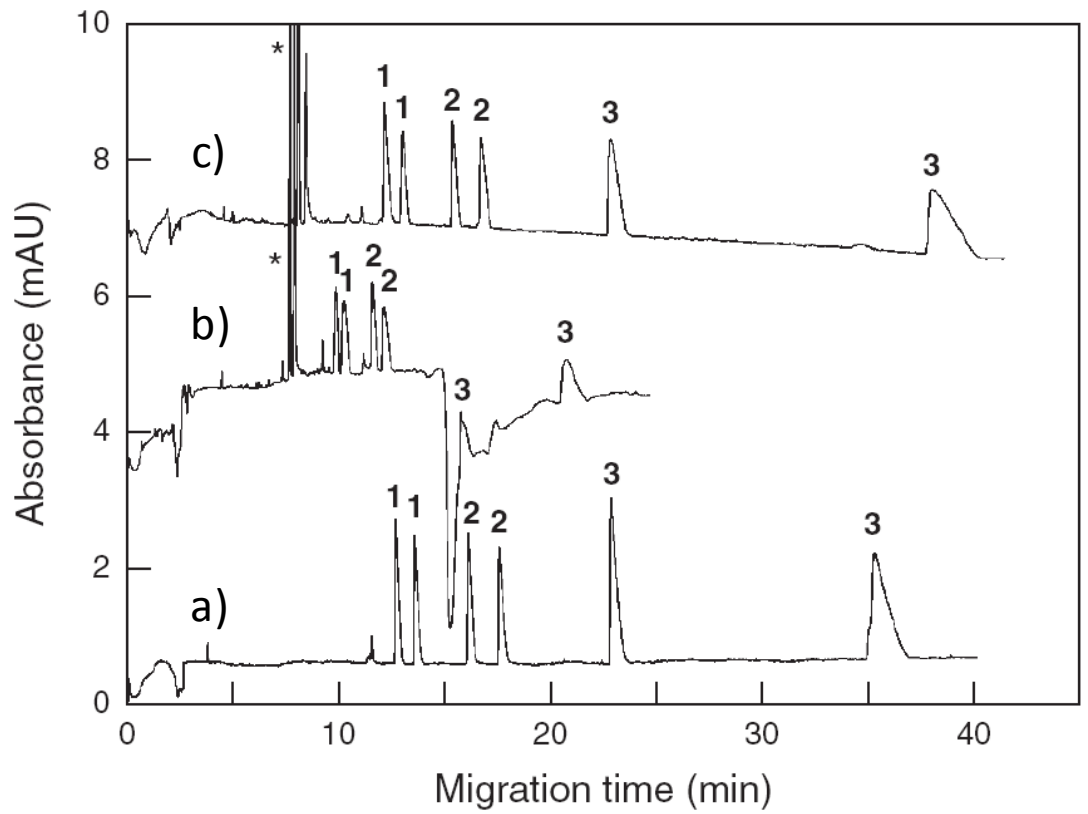


Figure 3

(A)

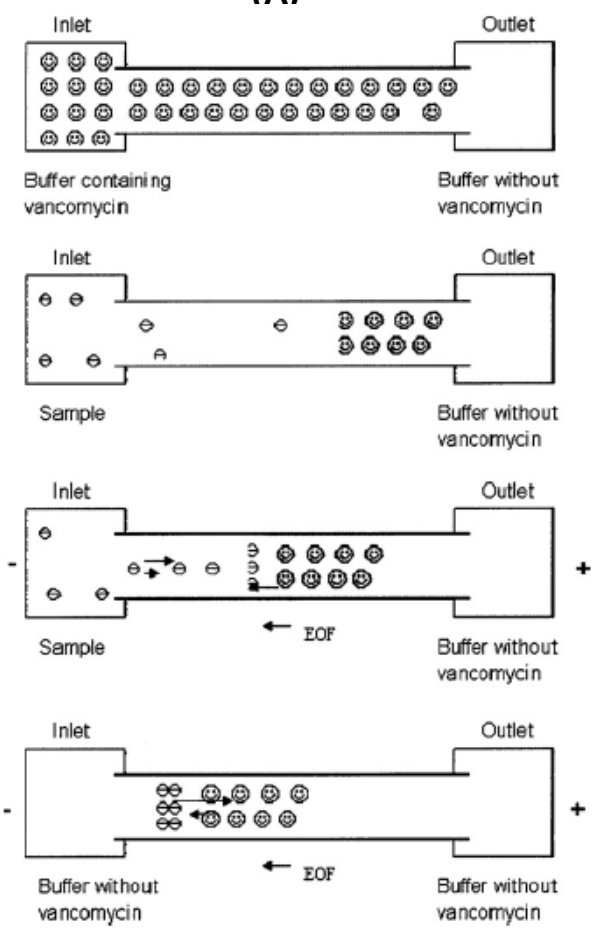

(B)

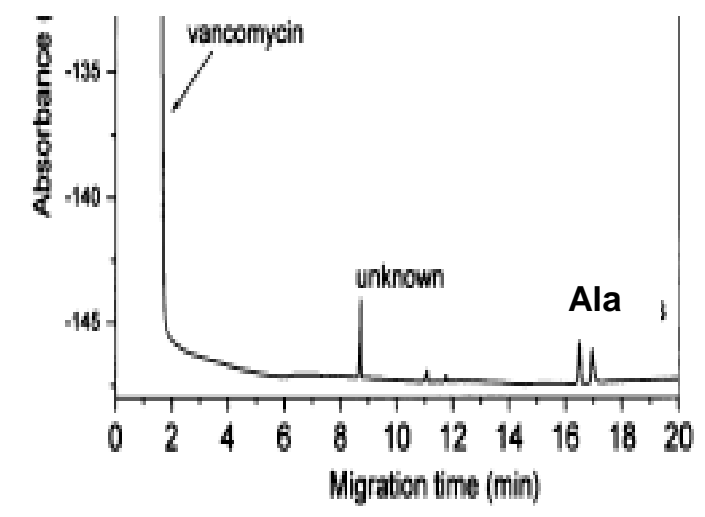

(C)
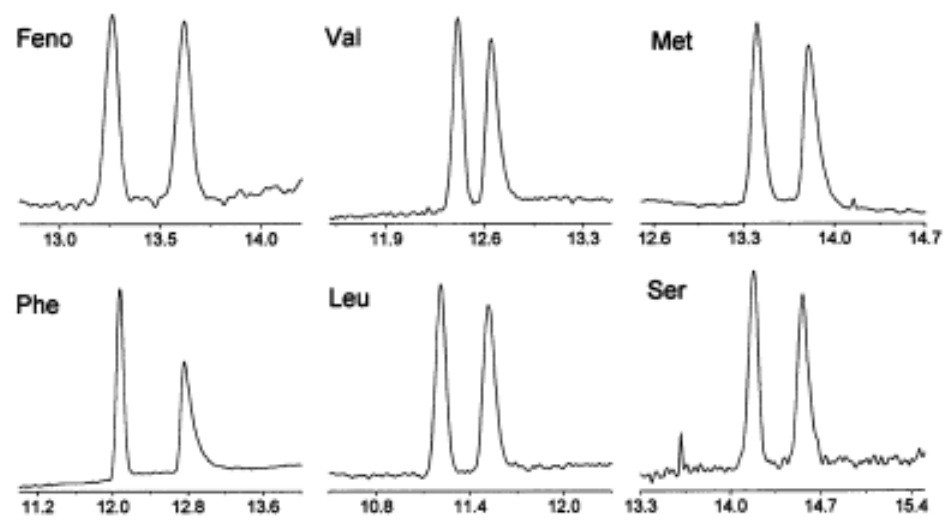

Ser

Migration time (min) 
Figure 4
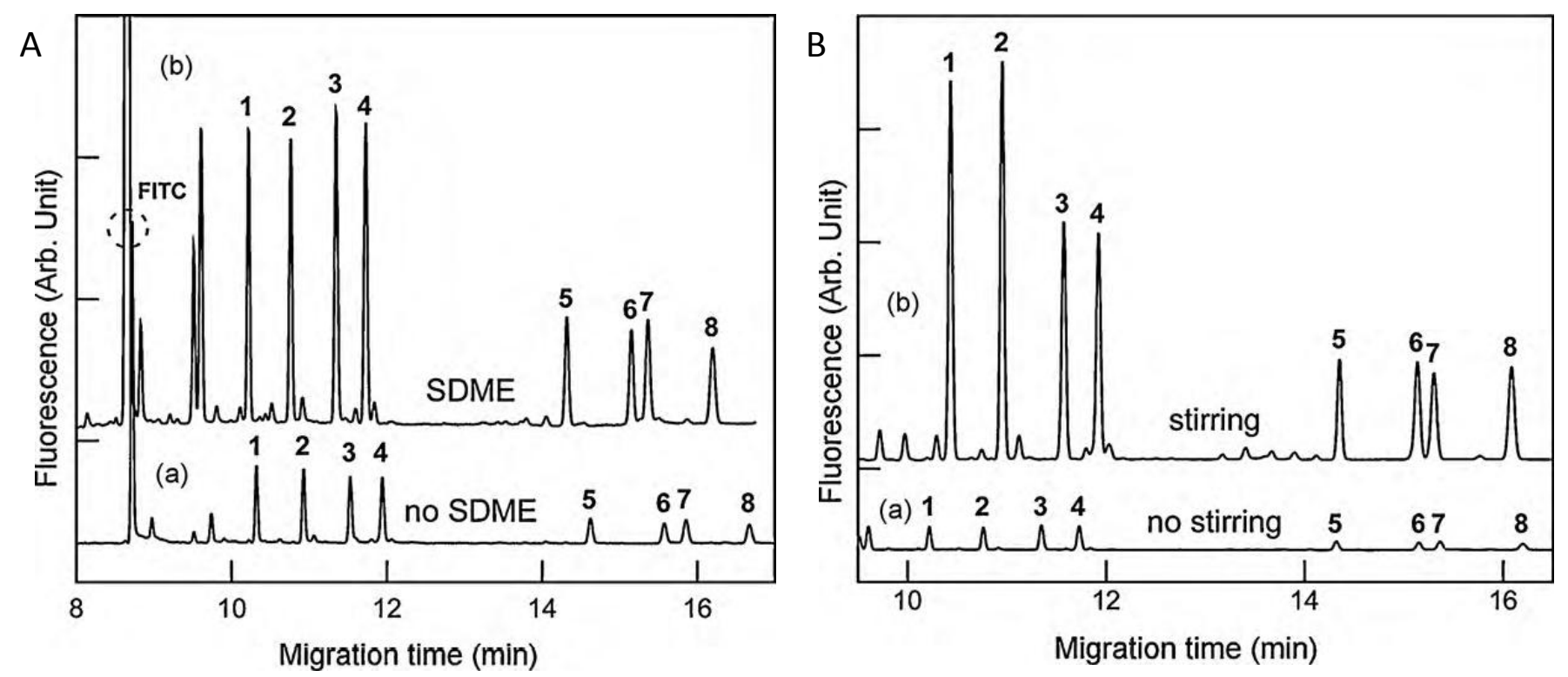
Figure 5
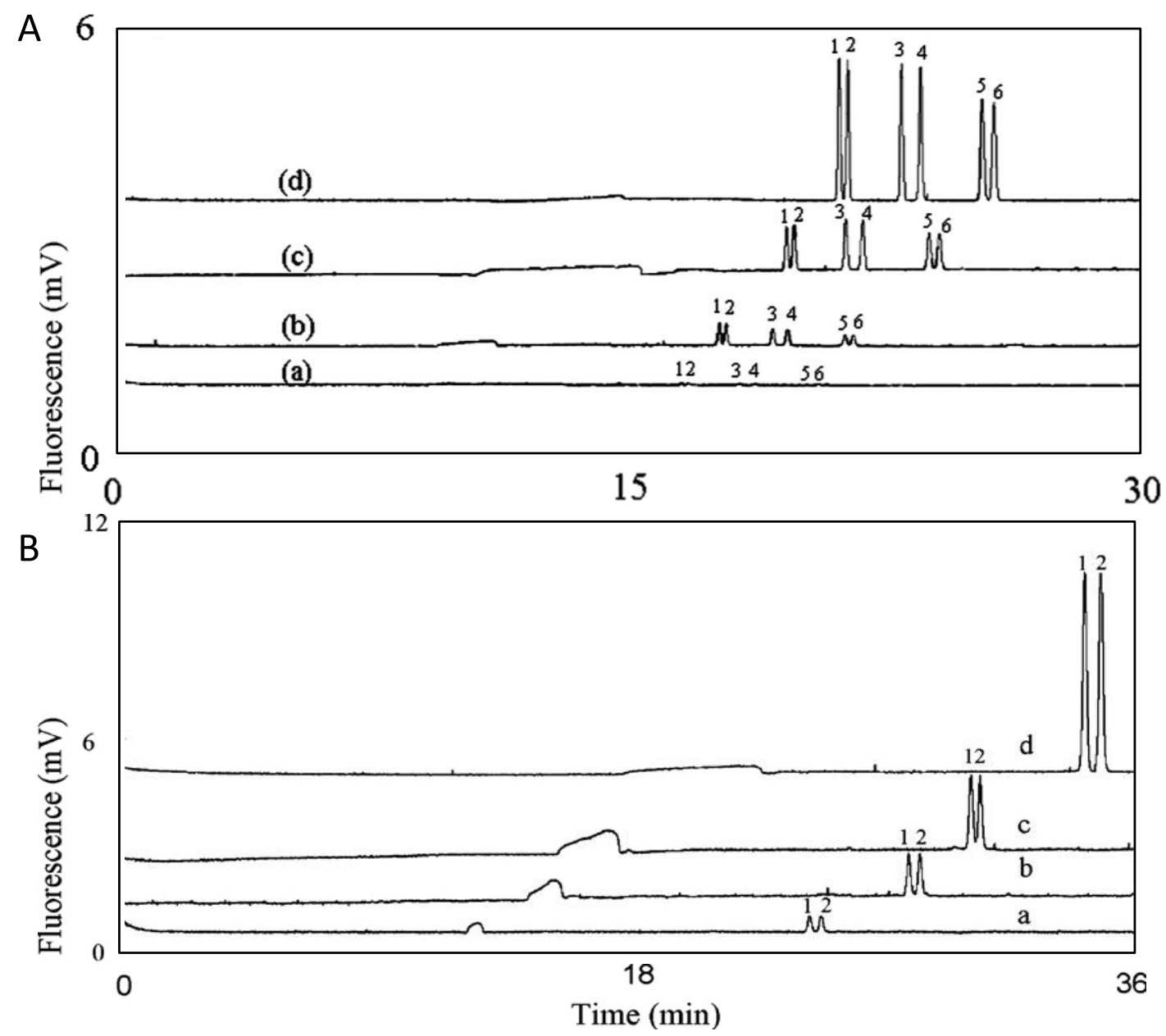


\section{Figure 6}
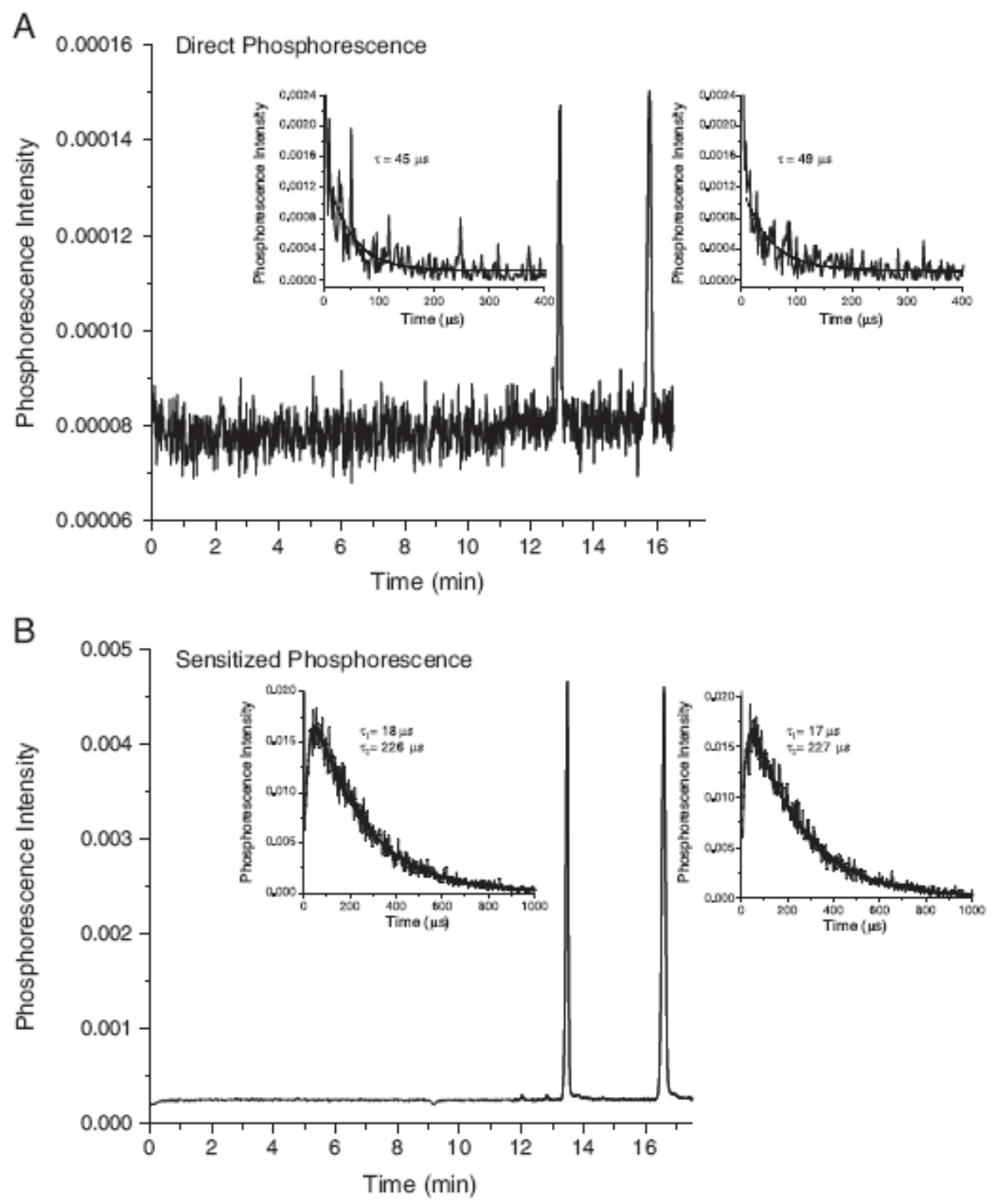
Figure 7

A (a)

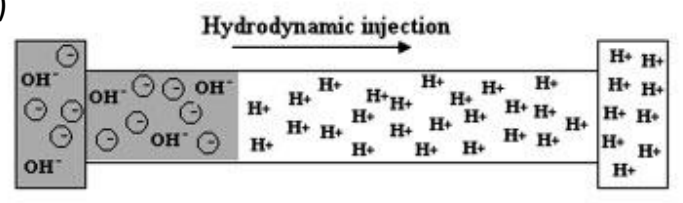

(b)

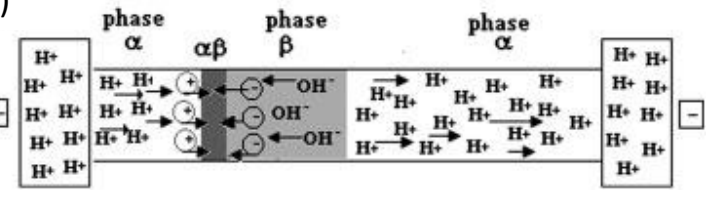

C

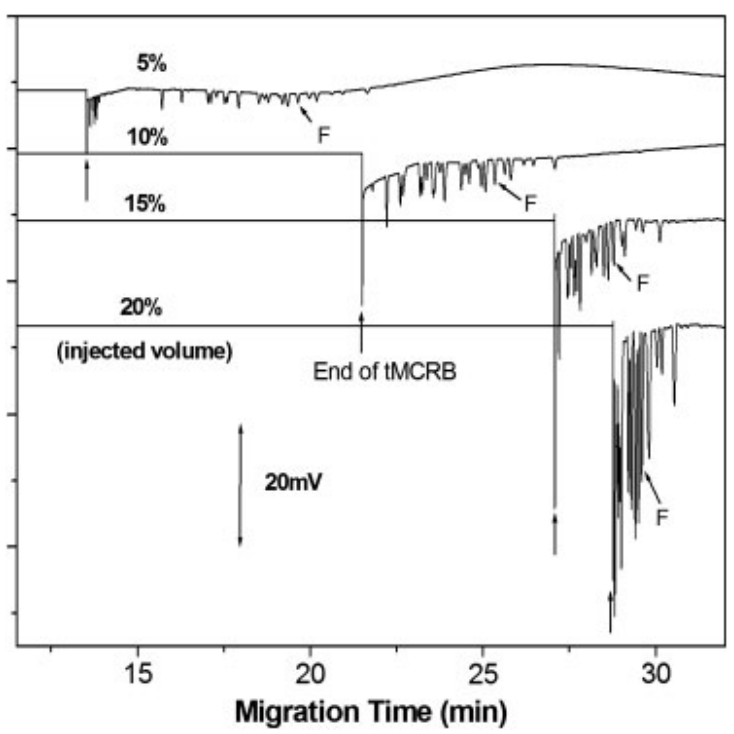

B

(1)

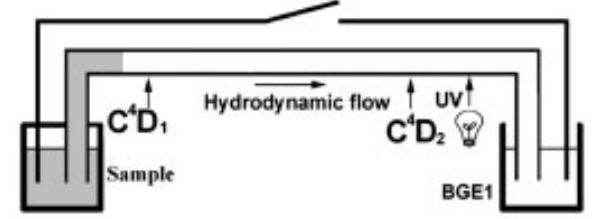

田司

(2)

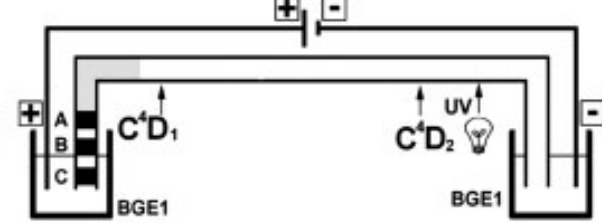

(3)

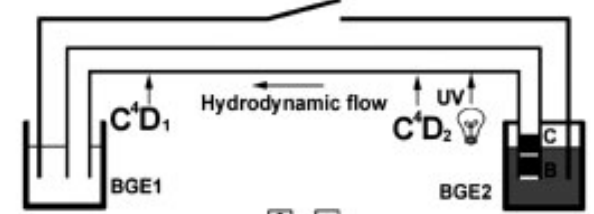

(4)

(5) 


\section{Figure 8}

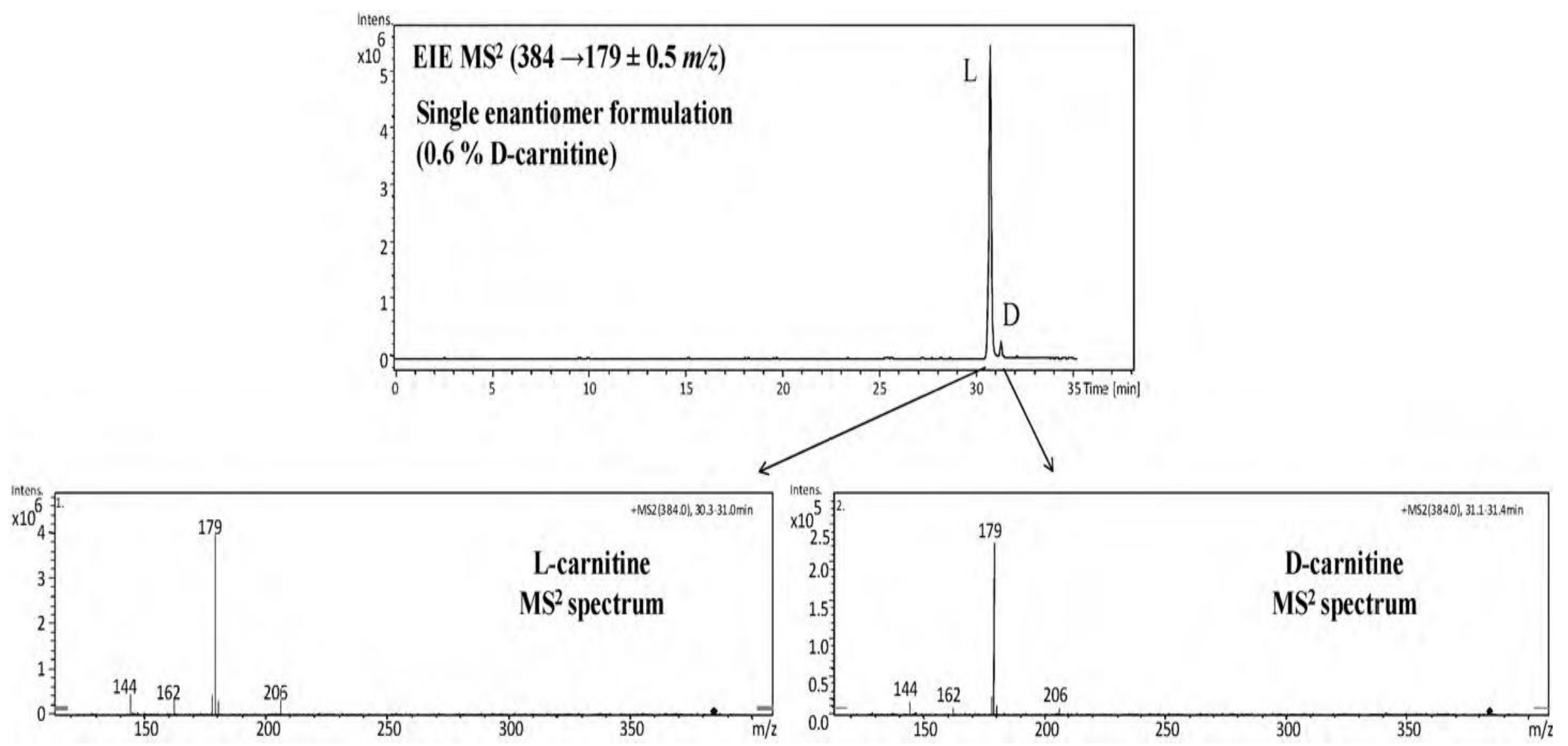


Table 1. Off-line sample treatment techniques employed for the enhancement of the sensitivity in chiral analysis by CE-UV.

\begin{tabular}{|c|c|c|c|c|c|c|}
\hline $\begin{array}{c}\text { Sample } \\
\text { treatment }\end{array}$ & $\begin{array}{c}\text { CE mode } \\
(\lambda \text { detection })\end{array}$ & Chiral analyte & Sample & BGE & LOD (M) & Ref. \\
\hline LLE & $\begin{array}{c}\mathrm{EKC} \\
(208 \mathrm{~nm})\end{array}$ & Propranolol, 4-hydroxypropranolol & $\begin{array}{l}\text { Czapek culture } \\
\text { medium }\end{array}$ & $\begin{array}{c}25 \mathrm{mM} \text { triethylamine/phosphoric acid (pH 9.0) } \\
+4 \%(\mathrm{w} / \mathrm{v}) \mathrm{CM}-\beta-\mathrm{CD}\end{array}$ & $\sim 1 \times 10^{-7}$ & 29 \\
\hline LLE & $\begin{array}{c}\mathrm{EKC} \\
(200 \mathrm{~nm})\end{array}$ & Midodrine, desglymidodrine & $\begin{array}{l}\text { Czapek culture } \\
\text { medium }\end{array}$ & $\begin{array}{l}70 \mathrm{mM} \text { acetate }(\mathrm{pH} 5.0) \\
+30 \mathrm{mM} \text { TM- } \beta-\mathrm{CD}\end{array}$ & $\sim 1 \times 10^{-7}$ & 30 \\
\hline LLE & $\begin{array}{c}\mathrm{EKC} \\
(214 \mathrm{~nm})\end{array}$ & $\begin{array}{l}\text { Trihexyphenidyl, primaquine, } \\
\text { Sulconazole, cetirizine }\end{array}$ & Rabbit blood & $\begin{array}{c}20 \mathrm{mM} \text { phosphate in water }(\mathrm{pH} 3.0) \\
\text { PFT: } 20 \mathrm{mM} \text { phosphate in DMSO/water }(40 / 60 \\
\mathrm{v} / \mathrm{v})(\mathrm{pH} 3.0)+10 \%(\mathrm{w} / \mathrm{v}) \text { amylose }(2 \mathrm{psi} \text { x } 240 \mathrm{~s})\end{array}$ & $\sim 3 \times 10^{-7}$ & 31 \\
\hline LLE & $\begin{array}{c}\mathrm{ACE} \\
(200 \mathrm{~nm})\end{array}$ & Tetrahydropalmatine & Herbs & 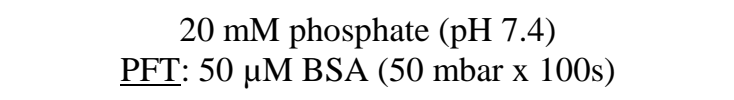 & $\sim 2 \times 10^{-8}$ & 32 \\
\hline SPE & $\begin{array}{c}\mathrm{EKC} \\
(220 \mathrm{~nm})\end{array}$ & $\begin{array}{l}\text { Ibuprofen, (R,S)-29- } \\
\text { hydroxyibuprofen, (RR,RS,SR,SS)- } \\
\text { 29-carboxyibuprofen }\end{array}$ & Human Urine & $\begin{array}{l}20 \mathrm{mM} \text { triethanoloamine/phosphoric acid ( } \mathrm{pH} 5.0) \\
+50 \mathrm{mM} \text { TM- } \beta-\mathrm{CD}\end{array}$ & $\sim(2-24) \times 10^{-7}$ & 33 \\
\hline SPE & $\begin{array}{c}\text { EKC } \\
(260 \mathrm{~nm})\end{array}$ & $\begin{array}{l}\text { Nicotine, cotinine, nornicotine, } \\
\text { anatabine, anabasine }\end{array}$ & Cigarettes & $\begin{array}{l}30 \mathrm{mM} \text { acetate }(\mathrm{pH} 5.0) \\
+8 \%(\mathrm{w} / \mathrm{v}) \mathrm{S}-\beta-\mathrm{CD}\end{array}$ & $\sim(9-20) \times 10^{-7}$ & 34 \\
\hline SLE & $\begin{array}{c}\text { EKC } \\
(243 \mathrm{~nm})\end{array}$ & $\begin{array}{c}\text { Methyl antcinate B, Antcin B, } \\
\text { Zhankuic acid C, Antcin A, Antcin C }\end{array}$ & $\begin{array}{l}\text { Antrodia } \\
\text { camphorata } \\
\text { fungus }\end{array}$ & $\begin{array}{c}20 \mathrm{mM} \text { borate }(\mathrm{pH} 9.3)+5 \% \mathrm{DMF} \\
+20 \mathrm{mM} \text { M- } \beta-\mathrm{CD}+30 \mathrm{mM} \text { SB- } \beta-\mathrm{CD}\end{array}$ & $\sim(1-9) \times 10^{-6}$ & 35 \\
\hline LPME & $\begin{array}{c}\mathrm{EKC} \\
(214 \mathrm{~nm})\end{array}$ & Amlodipine & $\begin{array}{l}\text { Plasma and } \\
\text { human urine }\end{array}$ & $\begin{array}{l}100 \mathrm{mM} \text { phosphate }(\mathrm{pH} 2.0) \\
+5 \mathrm{mM} \text { HP- } \alpha-\mathrm{CD}\end{array}$ & $\sim 7 \times 10^{-9}$ & 36 \\
\hline $\begin{array}{l}\text { Derivatization } \\
\text { with FMOC }\end{array}$ & $\begin{array}{c}\text { EKC } \\
(214 \mathrm{~nm})\end{array}$ & $\begin{array}{c}\text { Fenoprofen, } \\
\text { Ala, Leu, Met, Phe, Ser, Val }\end{array}$ & River water & $\begin{array}{l}100 \mathrm{mM} \text { Tris-phosphate }(\mathrm{pH} \text { 6.0) } \\
+2 \mathrm{mM} \text { vancomycin }\end{array}$ & $\sim(2-21) \times 10^{-9}$ & 37 \\
\hline
\end{tabular}

Ala, Alanine; Arg, arginine; Asn, asparagine; Asp, aspartic acid; CM- $\boldsymbol{\beta}-\mathbf{C D}$, carboxymethyl- $\beta-\mathrm{CD} ; \mathbf{D N S}$, dansyl; His, histidine; HP- $\alpha-\mathbf{C D}$ : 2 -hydroxypropyl- $\alpha-\mathrm{CD}$; HP- $\boldsymbol{\gamma}-$ CD, 2-hydroxypropyl- $\gamma$-CD; Ile, isoleucine; Leu, leucine; Lys, lysine; M- $\boldsymbol{\beta}$-CD, methyl- $\beta$-CD; MeOH, methanol; Met, methionine; Phe, phenylalanine; S- $\boldsymbol{\beta}-\mathbf{C D}$, sulphated-

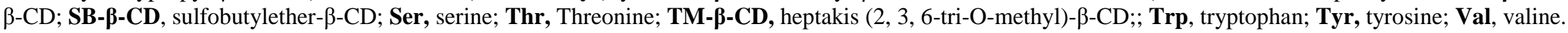


Table 2. On-line sample preconcentration techniques employed to enhance the sensitivity in chiral analysis by CE-UV.

\begin{tabular}{|c|c|c|c|c|c|c|c|}
\hline $\begin{array}{c}\text { Concentration } \\
\text { strategy }\end{array}$ & $\begin{array}{c}\text { CE mode } \\
(\lambda \text { detection })\end{array}$ & Analyte & Sample & BGE & Injection conditions & LOD (M) & Ref. \\
\hline LVSS-ASEI & $\begin{array}{c}\mathrm{EKC} \\
(214 \mathrm{~nm})\end{array}$ & $\begin{array}{l}\text { Fenoprofen, Ala, Leu, } \\
\text { Met, Phe, Ser, Val }\end{array}$ & River water & $\begin{array}{c}100 \mathrm{mM} \text { Tris- phosphoric acid (pH 6.0) } \\
+2 \mathrm{mM} \text { vancomycin }\end{array}$ & $\begin{array}{c}\text { Injection: } 34.45 \text { mbar x } 8 \text { min, } \\
\text { and }-5 \mathrm{kV} \times 12.5 \mathrm{~min} \\
\text { Sample solvent: } \mathrm{H}_{2} \mathrm{O}\end{array}$ & $(2-21) \times 10^{-9}$ & 37 \\
\hline NSM & $\begin{array}{c}\text { EKC } \\
(208 \mathrm{~nm})\end{array}$ & $\begin{array}{l}\text { Propranolol, } \\
\text { 4-hydroxypropranolol }\end{array}$ & $\begin{array}{l}\text { Czapek } \\
\text { culture } \\
\text { medium }\end{array}$ & $\begin{array}{c}25 \mathrm{mM} \text { triethylamine/phosphoric acid (pH 9.0) } \\
+4 \%(\mathrm{w} / \mathrm{v}) \mathrm{CM}-\beta-\mathrm{CD}\end{array}$ & $\begin{array}{l}\text { Injection: } 50 \text { mbar x } 20 \mathrm{~s} \\
\text { Sample solvent: } 1 / 10 \text { buffer }\end{array}$ & $\sim 10^{-7}$ & 29 \\
\hline FASS & $\begin{array}{c}\text { EKC } \\
(200 \mathrm{~nm})\end{array}$ & $\begin{array}{l}\text { Midodrine, } \\
\text { desglymidodrine }\end{array}$ & $\begin{array}{l}\text { Czapek } \\
\text { culture } \\
\text { medium }\end{array}$ & $\begin{array}{l}70 \mathrm{mM} \text { acetate }(\mathrm{pH} 5.0) \\
+30 \mathrm{mM} \text { TM- } \beta-\mathrm{CD}\end{array}$ & $\begin{array}{c}\text { Injection: } 10 \mathrm{kV} \times 5 \mathrm{~s} \text {, and } \\
\text { water plug: } 35 \mathrm{mbar} \times 5 \mathrm{~s} \\
\text { Sample solvent: } \mathrm{H}_{2} \mathrm{O} / \mathrm{MeOH} \\
(10 / 90 \mathrm{v} / \mathrm{v})\end{array}$ & $\sim 10^{-7}$ & 30 \\
\hline FASS & $\begin{array}{c}\text { ACE } \\
(200 \mathrm{~nm})\end{array}$ & Tetrahydropalmatine & $\begin{array}{l}\text { Corydalis } \\
\text { yanhusuo herb }\end{array}$ & 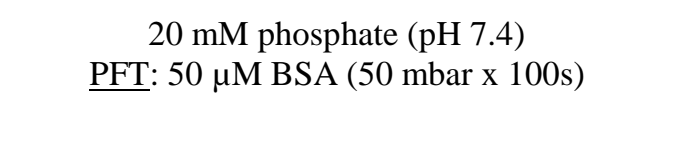 & $\begin{array}{l}\text { Injection: } 15 \mathrm{kV} \text { x } 12 \mathrm{~s} \text {, and } \\
\text { water plug: } 25 \text { mbar x } 8 \mathrm{~s} \\
\text { Sample solvent: } \mathrm{H}_{2} \mathrm{O}\end{array}$ & $\sim 2 \times 10^{-8}$ & 32 \\
\hline Sweeping & $\begin{array}{l}\text { MEKC } \\
(200 \mathrm{~nm})\end{array}$ & $\begin{array}{l}\text { Hexaconazole, } \\
\text { pentaconazole, } \\
\text { myclotbutanil }\end{array}$ & Standards & $\begin{array}{c}25 \mathrm{mM} \text { phosphate }(\mathrm{pH} 3.0)+50 \mathrm{mM} \text { SDS } \\
+40 \mathrm{mM} \text { HP- } \gamma-\mathrm{CD}\end{array}$ & $\begin{array}{l}\text { Injection: } 50 \text { mbar x } 70 \mathrm{~s} \\
\text { Sample solvent: buffer } \\
\text { without SDS and CD }\end{array}$ & $(3-7) \times 10^{-7}$ & 46 \\
\hline
\end{tabular}

Ala, Alanine; CM- $\beta-C D$, carboxylmethyl- $\beta-C D$; HP- $\boldsymbol{\gamma}$-CD, 2-hydroxypropyl- $\gamma-\mathrm{CD}$; Leu, leucine; MeOH, methanol; Met, methionine; Phe, phenylalanine; Ser, serine; TM- $\boldsymbol{\beta}-\mathbf{C D}$, heptakis $(2,3,6$-tri-O-methyl)- $\beta$-CD; Val, valine. 
Table 3. Alternative detection systems to UV detector, with or without other strategies, to improve sensitivity detection in chiral analysis by CE.

\begin{tabular}{|c|c|c|c|c|c|c|c|}
\hline Detection System & Other strategies & $\begin{array}{c}C E \\
\text { mode }\end{array}$ & Analyte & Sample & BGE & LOD (M) & Ref. \\
\hline $\begin{array}{c}\text { LIF } \\
\left(\lambda_{\mathrm{exc}}=488 \mathrm{~nm}\right)\end{array}$ & $\begin{array}{l}\text { FITC } \\
\text { derivatization } \\
+ \text { off-line } \\
\text { microdialysis }\end{array}$ & MEKC & Ser & $\begin{array}{l}\text { Extracellular fluid } \\
\text { of rat hypothalamus }\end{array}$ & $\begin{array}{c}15 \mathrm{mM} \text { borate }(\mathrm{pH} 10.2)+70 \mathrm{mM} \text { SDS } \\
+5 \%(\mathrm{v} / \mathrm{v}) \mathrm{MeOH} \\
+17.5 \mathrm{mM} \text { HP- } \beta-\mathrm{CD}+5 \mathrm{mM} \text { DM- } \beta-\mathrm{CD}\end{array}$ & $\sim 1 \times 10^{-10}$ & 50 \\
\hline $\begin{array}{c}\text { LIF } \\
\left(\lambda_{\mathrm{exc}}=488 \mathrm{~nm},\right. \\
\left.\lambda_{\mathrm{em}}=520 \mathrm{~nm}\right)\end{array}$ & $\begin{array}{l}\text { FITC } \\
\text { derivatization } \\
+ \text { on-line SDME }\end{array}$ & MEKC & $\begin{array}{l}\text { Ala, Asp, } \\
\text { Glu, Leu, }\end{array}$ & Standards & $\begin{array}{c}80 \mathrm{mM} \text { borate }(\mathrm{pH} 9.3) \\
+8 \mathrm{mM} \mathrm{STC}+12 \mathrm{mM} \beta-\mathrm{CD}\end{array}$ & $(1-3) \times 10^{-12}$ & 51 \\
\hline 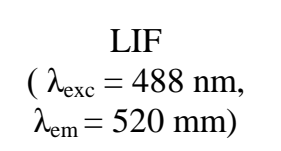 & $\begin{array}{l}\text { DTAF- } \\
\text { derivatization }\end{array}$ & MEKC & Asp & Pharmaceuticals & $\begin{array}{l}8 \mathrm{mM} \text { borate }(\mathrm{pH} 8.9)+10 \%(\mathrm{v} / \mathrm{v}) \mathrm{MeOH} \\
\quad+12 \mathrm{mM} \mathrm{SC}+0.8 \%(\mathrm{w} / \mathrm{v}) \mathrm{HSA}\end{array}$ & $3 \times 10^{-10}$ & 52 \\
\hline 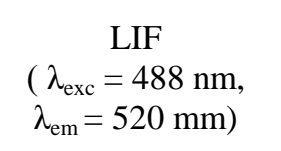 & $\begin{array}{l}\text { DTAF- } \\
\text { derivatization }\end{array}$ & MEKC & Glu & Pharmaceuticals & $\begin{array}{c}10 \mathrm{mM} \text { borate }(\mathrm{pH} 9.1)+5 \%(\mathrm{v} / \mathrm{v}) \mathrm{MeOH} \\
+12 \mathrm{mM} \mathrm{SC}+1.6 \%(\mathrm{w} / \mathrm{v}) \mathrm{HSA}\end{array}$ & $1 \times 10^{-10}$ & 52 \\
\hline $\begin{array}{c}\text { LIF } \\
\left(\lambda_{\mathrm{exc}}=475 \mathrm{~nm}\right)\end{array}$ & $\begin{array}{c}\text { FITC } \\
\text { derivatization }\end{array}$ & MEKC & Ser & $\begin{array}{l}\text { Midbrain of a } \\
\text { Parkinson's disease } \\
\text { mouse }\end{array}$ & 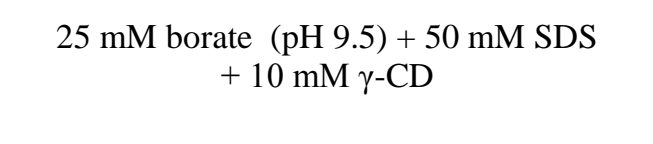 & $\sim 2 \times 10^{-8}$ & 53 \\
\hline $\begin{array}{c}\mathrm{LIF} \\
\left(\lambda_{\mathrm{exc}}=410 \mathrm{~nm}\right)\end{array}$ & $\begin{array}{l}\text { CBI derivatization } \\
+ \text { LVSS-sweeping }\end{array}$ & MEKC & Leu, Ile, Val & $\begin{array}{l}\text { Human urine and } \\
\text { plasma }\end{array}$ & $\begin{array}{c}100 \mathrm{mM} \text { tris-borate }(\mathrm{pH} 9.0)+150 \mathrm{mM} \text { SDS } \\
+50 \mathrm{mM} \text { HP- } \beta-\mathrm{CD}\end{array}$ & $\sim 2 \times 10^{-10}$ & 54 \\
\hline $\begin{array}{c}\text { LIF } \\
\left(\lambda_{\mathrm{exc}}=410 \mathrm{~nm}\right)\end{array}$ & $\begin{array}{c}\text { NAD } \\
\text { derivatization } \\
+ \text { LVSS-sweeping }\end{array}$ & MEKC & Asp & $\begin{array}{l}\text { Cerebrospinal fluid, } \\
\text { soymilk, beer }\end{array}$ & $\begin{array}{c}150 \mathrm{mM} \text { tris-borate }(\mathrm{pH} 9.0)+150 \mathrm{mM} \text { SDS } \\
+60 \mathrm{mM} \text { HP- } \beta-\mathrm{CD}\end{array}$ & $\sim 2 \times 10^{-10}$ & 55 \\
\hline
\end{tabular}




$$
\begin{gathered}
\text { LIF } \\
\left(\lambda_{\mathrm{exc}}=280 \mathrm{~nm},\right. \\
\left.\lambda_{\mathrm{em}}=266 \mathrm{~nm}\right)
\end{gathered}
$$

LIF

$\left(\lambda_{\mathrm{em}}=266 \mathrm{~nm}\right)$

Phosphorescence

$\left(\lambda_{\mathrm{exc}}=465 \mathrm{~nm}\right)$

Phosphorescence

$\left(\lambda_{\text {exc }}=266 \mathrm{~nm}\right)$

Phosphorescence $\left(\lambda_{\text {exc }}=266 \mathrm{~nm}\right)$

ECL

LLE + FASS

Conductivity $\left(\mathrm{C}^{4} \mathrm{D}\right)$

Conductivity $\left(C^{4} \mathrm{D}\right)$

ESI-MS (Q)

FASS

FASS

LLE

tMCRB

PFT
EKC

EKC

EKC

EKC

EKC

MEKC

2-hydroxydecanoic acid,

2D-CE
$\operatorname{Trp}$

Propranolol

Camphorquinone

Camphorquinone

Bupropion

Dioxopromethazine

Lactic acid,

$\alpha$-hydroxybutyric acid, 2-hydroxycaproic acid,

2-hydroxyoctanoic acid,

$$
\text { Asp, Glu }
$$

Phe, Thr

Standards

Standards

Standards

Cured dental resin

Pharmaceuticals

and urine

Human urine

Milk, yogurt

Serum

Ala, DL

Gly-D-Phe, Gly-L-Phe
$1 \mathrm{mM}$ phosphate ( $\mathrm{pH} 2.5$ )

$+0.15 \%(\mathrm{w} / \mathrm{v}) \mathrm{HS}-\beta-\mathrm{CD}$

$7 \times 10^{-11}$

$2 \mathrm{mM}$ acetate $(\mathrm{pH} 2.5)$

$+0.14 \%$ (w/v) HS- $\alpha-C D$

$\sim 2 \times 10^{-10}$

$25 \mathrm{mM}$ borate $(\mathrm{pH} 9.0)$ $+20 \mathrm{mM} \alpha-\mathrm{CD}+10 \mathrm{mM}$ CM- $\beta-\mathrm{CD}$

$(2-10) \times 10^{-7}$

$25 \mathrm{mM}$ borate $(\mathrm{pH} 9.0)+10^{-5} \mathrm{M} 2,6-\mathrm{NS}$ $+20 \mathrm{mM} \alpha-\mathrm{CD}+10 \mathrm{mM}$ CM- $\beta-\mathrm{CD}$

$(4-5) \times 10^{-8}$

$25 \mathrm{mM}$ phosphate ( $\mathrm{pH} 3.0)$

$+2 \times 10^{-4} \mathrm{M}$ biacetyl $+5 \mathrm{mM} \mathrm{S}-\alpha-\mathrm{CD}$

$2 \times 10^{-7}$

$25 \mathrm{mM}$ tris-phosphate/40 $\mathrm{mM}$ borate $(\mathrm{pH} 2.5)$

$$
+16.5 \mathrm{mM} \beta-\mathrm{CD}
$$

$10 \mathrm{mM}$ Tris $/ 4.4 \mathrm{mM}$ maleic acid $(\mathrm{pH} 7.35)$ $+0.03 \mathrm{mM} \mathrm{CTAB}+5 \mathrm{mM}$ vancomycin

$\sim(2-3) \times 10^{-6}$

2.3 $\mathrm{M}$ acetic acid $(\mathrm{pH} 2.1)$ for $1^{\text {st }}$ dimension and $2.3 \mathrm{M}$ acetic acid ( $\mathrm{pH} 2.1)$

$+10 \mathrm{mM} 18 \mathrm{C}_{6} \mathrm{H}_{4}$ for $2^{\text {nd }}$ dimension

$2 \mathrm{M}$ acetic acid ( $\mathrm{pH} 2.15)$;

PFT: $3 \mathrm{M}$ acetic acid (pH 2.00)

$+5 \mathrm{mM} 18 \mathrm{C}_{6} \mathrm{H}_{4}(50 \mathrm{mbar}$ for $960 \mathrm{~s})$ 


\section{$\mathrm{ESI}^{-M S^{2}}$ (IT)}

PFT

EKC

$\mathrm{N}$-methylsalsolinol, salsolinol, 1-benzyl$1,2,3,4-$

tetrahydroisoquinoline

\section{ESI-MS (TOF)}

FITC derivatization

FMOCderivatization

\begin{abstract}
EKC
Ala, Arg, Asn, Asp, Glu,
\end{abstract}

EKC

Carnitine

Thyroxine

EKC
In vitro study in an

incubation solution

Soy, vinegar

Pharmaceuticals

Pharmaceuticals
$20 \mathrm{mM}$ ammonium acetate ( $\mathrm{pH}$ 5.5); $(\mathrm{pH} 5.5)+1 \mathrm{mM} \mathrm{S}-\beta-\mathrm{CD}(100$ mbar x 50)

$50 \mathrm{mM}$ ammonium carbonate (pH 8.0)

$$
+0.5 \mathrm{mM} \mathrm{CD}_{3} \mathrm{NH}_{2}
$$

$0.5 \mathrm{M}$ ammonium formate $(\mathrm{pH} 2.5)$ $+0.2 \%$ Succ- $\gamma-\mathrm{CD}$ PFT: $20 \mathrm{mM}$ acetic acid/ammonium acetate

$\sim 1 \times 10^{-6}$

$\sim$

$(2-19) \times 10^{-7}$

$\sim 6 \times 10^{-8}$

$10 \mathrm{mM}$ borate $(\mathrm{pH} 9.6)+10 \%$ acetonitrile $\sim 4 \times 10^{-7}$

ICP-MS $+\mathrm{Cu}(\mathrm{II}) / \mathrm{L}$-proline $(0.05 \mathrm{mM} / 0.40 \mathrm{mM})$

2,6-NS, 2,6-naphthalenedisulfonic acid; Ala, alanine; Arg, arginine; Asn, asparagine; Asp, aspartic acid; BrNS, 1-bromo-4-naphthalene sulfonic acid; CBI, cyanobenz[f]isoindole; $\mathbf{C}^{\mathbf{4}} \mathbf{D}$, contactless conductivity detection; $\mathbf{C D}_{\mathbf{3}} \mathbf{N H}_{2}$, 3-monodeoxy-3-monoamino- $\beta$-CD; $\mathbf{C M -} \boldsymbol{\beta}-\mathbf{C D}$, carboxymethyl$\beta$-CD; DM- $\boldsymbol{\beta}$-CD, 2,6-O-Dimethyl- $\beta$-CD; DTAF, 5-(4,6-dichloro-s-triazin-2-ylamino)fluorescein; Glu, glutamic acid; Gly, glycine; HP- $\boldsymbol{\beta}$-CD, 2hydroxypropyl- $\beta-C D$; HS- $\alpha-C D$ : high sulphated- $\alpha-C D$ HS- $\beta-C D$ : high sulphated- $\beta-C D$; Ile, isoleucine; Leu, leucine; MeOH, methanol; NAD, naphthalene-2,3-dicarboxaldehyde; PEO, poly(ethylene oxide); Phe, phenylalanine; Poly-L-SUCIL, polysodium N-undecenoxycarbonyl-Lisoleucinate; Q, quadrupole analyzer; S- $\alpha-\mathbf{C D}$, sulphated- $\alpha-C D$; $\mathbf{S}-\boldsymbol{\beta}-\mathbf{C D}$, sulphated- $\beta-C D$; SC, sodium cholate; Ser, serine; STC, sodium taurodeoxycholate; Succ- $\gamma-\mathbf{C D}$, succinyl- $\gamma-\mathrm{CD}$; Thr, Threonine; Tris, tris(hydroxymethyl)aminomethane; Trp, tryptophan; Val, valine. 